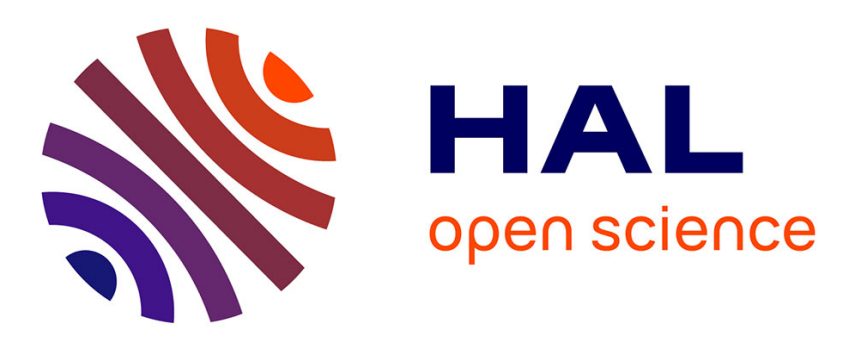

\title{
A probabilistic approach to study the effect of machined surface states on HCF behavior of a AA7050 alloy
}

Foued Abroug, Etienne Pessard, Guenaël Germain, Franck Morel

\section{To cite this version:}

Foued Abroug, Etienne Pessard, Guenaël Germain, Franck Morel. A probabilistic approach to study the effect of machined surface states on HCF behavior of a AA7050 alloy. International Journal of Fatigue, 2018, 116, pp.473-489. 10.1016/j.ijfatigue.2018.06.048 . hal-02281610

\section{HAL Id: hal-02281610 https://hal.science/hal-02281610}

Submitted on 9 Sep 2019

HAL is a multi-disciplinary open access archive for the deposit and dissemination of scientific research documents, whether they are published or not. The documents may come from teaching and research institutions in France or abroad, or from public or private research centers.
L'archive ouverte pluridisciplinaire HAL, est destinée au dépôt et à la diffusion de documents scientifiques de niveau recherche, publiés ou non, émanant des établissements d'enseignement et de recherche français ou étrangers, des laboratoires publics ou privés. 


\title{
A probabilistic approach to study the effect of machined surface states on HCF behavior of a AA7050 alloy
}

\author{
Foued Abroug*, Etienne Pessard, Guenaël Germain, Franck Morel \\ LAMPA, Arts et Métiers ParisTech Angers, 2 Bd du Ronceray, 49035 Angers, France
}

\author{
A R T I C L E I N F O \\ Keywords: \\ High speed machining \\ Surface defect \\ High cycle fatigue \\ Probabilistic Kitagawa-Takahashi diagram \\ Weakest link concept
}

\section{A B S T R A C T}

The aim of this study is to understand the impact of periodic surface micro-geometry patterns (obtained by High Speed Machining process) on the fatigue behavior of the AA7050 aluminium alloy and to define a proper defect acceptability criterion. It must be able to account for a large range of surface defects and of component sizes and geometries (wings, brackets, frames, etc.). A vast experimental campaign under fully reversed plane bending loads containing different surface states has been undertaken to characterize the effect of the surface topography on the fatigue behavior. The results show that the fatigue strength decreases when the surface roughness is significantly degraded. In order to predict the influence of the surface condition on the fatigue behavior, a numerical approach based on the real surface topology has been developed. It is shown that the numerically identified crack initiation sites are in agreement with the experimental results. A probabilistic approach based on the weakest link concept, associated with the definition of a stress based crack initiation threshold has been integrated in a FE model. This approach leads to a probabilistic diagram inspired from the Kitagawa type diagram, which explains the relationship between the surface and the scale effect on the fatigue strength.

\section{Introduction}

Machining is a manufacturing process largely used in the aerospace industry. Milling is one type of machining process that consists in using rotary cutters to remove materials from a workpiece. The process induces residual stresses, surface roughness and, to a lesser extent, work hardening. These surface integrity parameters can delay or enhance crack initiation at the part surface. The latter is a critical location for fatigue crack initiation and milling is most of the time seen as detrimental to the fatigue life due to the microscopic mechanical concentrators created. One of the greatest challenges when designing milled parts against fatigue is to find out to what extent a given surface microgeometry is critical and to identify the relevant roughness parameters to be used for the fatigue strength prediction. When dealing with this issue, the effects of the loading mode, the microstructure and the component size must also be taken into account.

The work presented in this paper deals with the machined surface states of structural aeronautical components. The material under investigation is the 7050-T7451 aluminium alloy (Al Zn6CuMgZr). During HSM (High Speed Machining) of aircraft parts, geometrical defects can be created. Mismatch may appear due to the gap left between two consecutive passes of the machining tool. Chatter can also be created due to the tool/part vibrations which may occur during different types of machining. One of the main objectives of the research project is to build a fatigue life predictive model that accounts for the surface integrity parameters induced by milling, and from which a proper defect acceptability criterion can be proposed (defect size, depth, surface roughness, etc.). It must be able to account for a large range of surface defects and of component sizes and geometries. By reducing costly trial and error experimental campaigns, this approach would be an important asset for the quality control of aeronautical parts.

Several studies in the literature pointed out that, by the local thermomechanical effects induced, machining can change the surface integrity of manufactured parts and therefore modify their fatigue strength [1-5]. Changing the cutting conditions can also generate a different surface topology and therefore a new fatigue life $[1,6]$. For instance, Shahzad [2] pointed out that the fatigue resistance of machined aluminium alloy shows a significant decrease when surface roughness increases. Different literature studies [7-9] addressed the issues of residual stresses and microstructure variation due to the machining process. For the plain milling process, Brunet [1] showed that residual stresses induced by the machining process have an important effect on the fatigue response. On the contrary, for the end milling process of the AA-7XXX alloys, the studies tend to show that residual stresses and the microstructure variations are mainly located in the first

\footnotetext{
* Corresponding author.

E-mail address: Foued.Abroug@ensam.eu (F. Abroug).
} 
50 micrometers below the surface leading to a slight effect compared to the surface topology $[1,10]$.

Regarding the fatigue life prediction of AA-7XXX alloy and the effect of machining, different approaches proposed in the literature could be good candidates to account for the effect of the surface topology due to turning, shaping, milling or even abrasion. In the first category of approach, both roughness parameters (i.e. the arithmetic linear roughness $R_{a}$ or surface roughness $S_{a}$ ) and geometrical characteristics of groove due to machining are used to define scalars that are supposed to be relevant fatigue damage indicators [11-14]. FE calculations can also be conducted to assess the stress concentration in the case of complex geometric defects [10]. Another way is to directly predict the fatigue strength via the empirical criterion of Murakami [15] in its adapted formulation to the machined surface states.

The second category is composed of non-local approaches, like the critical distance [16] originally proposed by Taylor [17,18] and that considers a mean stress value evaluated over a line, a surface or a given volume. The efficiency of non local approaches has been demonstrated in a number of applications, for instance for notched components [19], specimens containing internal defects [20] or surface defects [21].

The last category is the one of probabilistic approach. In the high cycle fatigue regime, the weakest link concept $[22,23]$ is often used to predict the effect of manufacturing processes on the fatigue life of components [24-28]. Initially developed to take into account the effect of defects on cast alloys such as spheroidal graphite (SG) cast iron, this type of approach has been extended to account for the scatter on different kind of hetereogenities population (inner defects population [29], grains mechanical resistance [30] and surface defects population [31]).

In the case of machining, $[3,4]$ proposed to characterize the microgeometry by defect size distributions. A two-scale approach taking account of the probabilistic description of the geometrical defects induced by the milling process is used to predict the endurance limit of specimens subjected to four-point bending fatigue tests. The approach developed by $[3,4]$ takes into account all the surface defect size distribution and allows for a link between the fatigue limit scatter and the studied defect population.

Despite the great number of studies and models dealing with the effect of machining in the literature, the fatigue strength of machined components is still an open question. This is all the most true when, as in the present study, a wide range of defects and surface conditions of machined components presenting different sizes and shapes has to be faced.

The investigation described in this paper is both experimental and numerical. A large experiment campaign is conducted on specimens with different surface topology obtained by end milling process with different milling conditions. The experimental results allow to plot a diagram inspired from the Kitagawa-Takahashi type diagram [32] showing the effect of the surface roughness on the fatigue life. The observed behavior is modeled using Finite Element simulations together with the weakest link concept. Two different approaches are tested, surface and volume-based approaches developed and presented in a previous study [31]. The suitability and limitations of these approaches are discussed based on the comparisons with experimental results.

\section{The AA7050-T7451 alloy and the experimental procedure}

\subsection{The material}

The material under investigation is the AA 7050 Aluminum alloy (Al $\mathrm{Zn6CuMgZr}$ ) and is provided in a $30 \mathrm{~mm}$ thick sheet form.

The chemical composition of the AA7050-T7451 alloy is given in Table 1 . The rolling process to obtain the material sheet generates a high recrystallization rate. Areas of consolidation of recrystallized and non-recrystallized grains can reach a few millimeters of length. Grains
Table 1

Chemical composition of the AA7050-T7451 alloy, in weight percentage.

\begin{tabular}{cccccccccc}
\hline Element & $\mathrm{Al}$ & $\mathrm{Zn}$ & $\mathrm{Cu}$ & $\mathrm{Mg}$ & $\mathrm{Zr}$ & $\mathrm{Ti}$ & $\mathrm{Si}$ & $\mathrm{Fe}$ & $\mathrm{Mn}$ \\
\hline Weigth (\%) & bal. & 6.027 & 2.221 & 1.847 & 0.102 & 0.039 & 0.038 & 0.095 & 0.01 \\
\hline
\end{tabular}

have dimensions ranging from 5 to $300 \mu \mathrm{m}$ in rolling and transverse directions, and 5-50 $\mu \mathrm{m}$ in depth (see Fig. 1). Different types of intermetallic particles $\left(\mathrm{Mg}_{2} \mathrm{Si}, \mathrm{Al}_{7} \mathrm{Cu}_{2} \mathrm{Fe}, \mathrm{MgZn}_{2}, \mathrm{AlCuZn}\right.$, etc...) are present at the grain boundaries and in the recrystallized grains (Fig. 1). These particles can be at the origin of crack initiation under fatigue loading due to their brittle nature [2,33].

Monotonic tensile tests are conducted, in respect to the standard ASTM E8M-04, using two extensometers to measure the strain in the length and width of the specimen (geometry shown in Fig. 2). Two to Three specimens are tested for each direction $\left(0^{\circ}, 45^{\circ}\right.$ and $90^{\circ}$ to the rolling direction). The anisotropy is slightly marked and the ductility is limited with a maximum elongation around $13 \%$ (Table 2). In addition, microhardness measurements are conducted along the sheet depth and show slight variations around $157 \mathrm{Hv} / 0.5$.

Specimens are machined out of the center of the aluminium sheet. The machining process can change the surface integrity of manufactured parts and therefore change their fatigue strengths. Several studies have shown that in the case of end milled AA7xxx alloys, the geometrical aspect of the surface is the dominant factor on fatigue behavior $[1,2,10]$. Residual stresses as well as the microstructural changes are, in this context, localized to a small thickness layer and will therefore be neglected in the presented study.

\subsection{Fatigue experimental conditions}

All fatigue tests are carried out under fully reversed plane bending $(\mathrm{R}=-1)$. A specific specimen geometry is developed for this study (Fig. 3). Four chanfrens are machined to avoid corner cracks. Under bending loading, maximum stress is located in the upper (or lower) surface of the gauge length specimen. Tests are conducted at a frequency of $75 \mathrm{~Hz}$ with a resonant Rumul Cracktronic type machine at room temperature and ambient air. Fatigue tests are stopped when a frequency drop of $0.7 \mathrm{~Hz}$ is reached (wich corresponds to a minimum crack length of $5 \mathrm{~mm}$ ) or when $2.10^{6}$ cycles are reached.

Fatigue tests are carried out according to the StairCase method described by Dixon and Mood [34] and according to the standard ISO12107 [35]. The step for the StairCase method is $10 \mathrm{MPa}$ and the fatigue strength assessed for $2.10^{6}$ cycles. 15 samples per batch are used except for the M5.5 surface state batch, where 10 specimens are tested. Specimens that survived in the staircase procedure were retested at a higher load in order to identify the Wöhler curve shape. These retested specimens simply give an overview of the SN curve in the finite fatigue life regime and do not offer any additional information since they already survived a lower loading level and hence do not represent the original population.

In order to assess the machining surface state effect on the fatigue behavior, three surface state batches are prepared via milling operation with a KX30 type high speed machining center. Some specimens are mirror-polished so as to have a surface state with a perfect surface plane geometry and a reference for the fatigue tests. The notation used for the different machining batches is referred to the arithmetic mean surface height $S_{a}$ (i.e: M1.1: Machined surface state with an arithmetic mean surface height value $S_{a}=1.1 \mu \mathrm{m}$ ).

The various surface states used in this study are shown in Fig. 5 and are as follows:

- M1.1 surface, the surface state of industrially machined components. This batch is machined using a tool with a high nose radius and the usual industrial cutting conditions. 


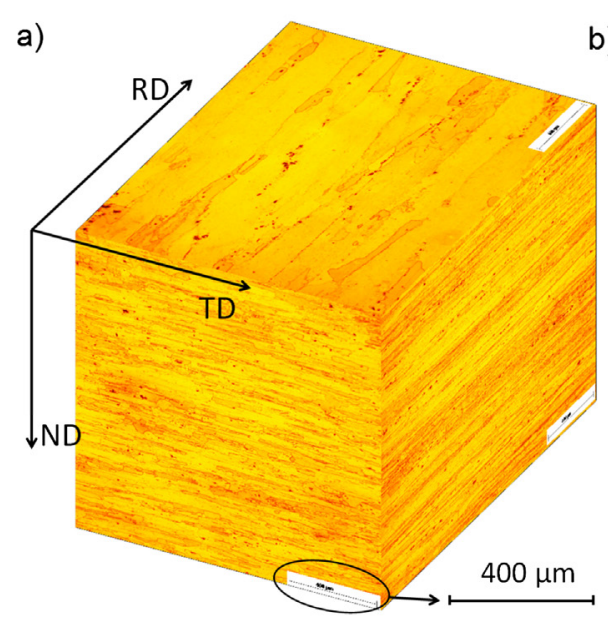

b)

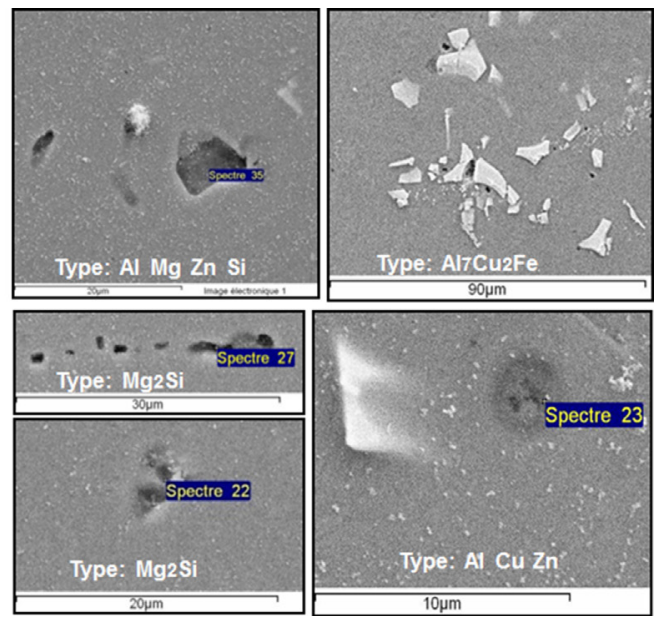

Fig. 1. (a) AA7050-T7451 alloy RD: Rolling Direction, TD: Transverse Direction, ND: Normal Direction, (b) SEM images of the intermetallic particles observed on the AA7050 alloy sheet.

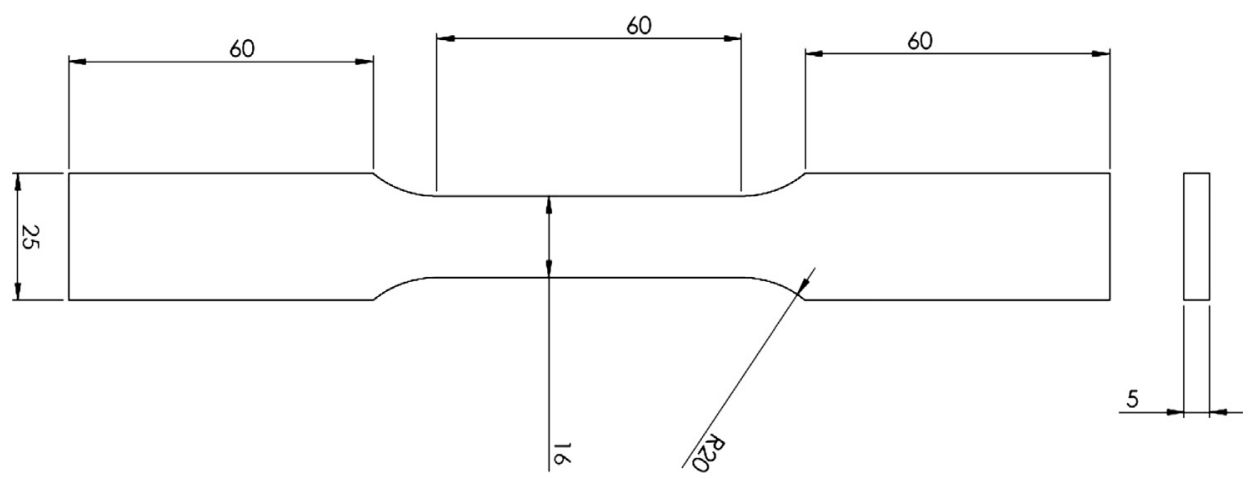

Fig. 2. Geometry of tensile specimen.

Table 2

Monotonic properties of the AA7050 alloy.

\begin{tabular}{cccc}
\hline $\begin{array}{c}\text { Rolling } \\
\text { Direction }\end{array}$ & $\begin{array}{c}\text { Yield Stress } \\
\text { (MPa) }\end{array}$ & $\begin{array}{c}\text { Utlimate Tensile } \\
\text { Strength (MPa) }\end{array}$ & $\begin{array}{c}\text { Tensile Elongation } \\
(\%)\end{array}$ \\
\hline $0^{\circ}$ & 475 & 635 & 12.3 \\
$45^{\circ}$ & 428 & 496 & 13.9 \\
$90^{\circ}$ & 475 & 538 & 11.9 \\
\hline
\end{tabular}

- M4.2 surface, voluntarily degraded. This batch is machined using a tool with a low nose radius and degraded cutting conditions.

- M5.5 surface, voluntarily highly degraded. The M5.5 surface state is machined under the same cutting conditions as for the M4.2 batch, but with a very slight forward inclination of the tool (offset angle of approximately $0.05^{\circ}$ ) (Fig. 4). In this case, the rear teeth is not in contact with the surface specimen, which greatly modifies the surface state (Fig. 6). The difference between the two surface states M4.2 and M5.5 is shown in Figs. 6 and 7.

- P0 surface, this surface state is manually polished in the laboratory and used as the reference in fatigue.

The machining conditions for the batches M1.1, M4.2 and M5.5 are summarized in Table 3.

After machining, the surface topography of the specimens is scanned with a 3D BRUKER type profilometer (see Fig. 6). This profilometer, with a vertical resolution along the $Z$ axis of $10 \mathrm{~nm}$ and a spatial resolution along the $\mathrm{X}$ and $\mathrm{Y}$ axes of $1.9 \mu \mathrm{m}$, provides high quality scans and accurate measurements of the different surface parameters. The average usual surface state parameters (Eqs. (1)-(6)) for the different batches are characterized and presented in Table 4.
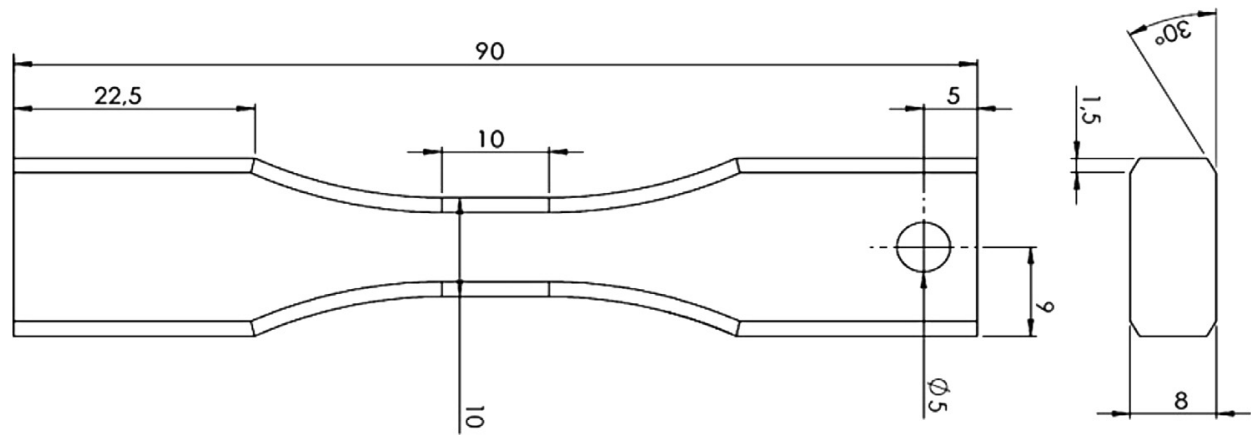

Fig. 3. Geometry of plane bending specimen showing four chanfrens. 
a)

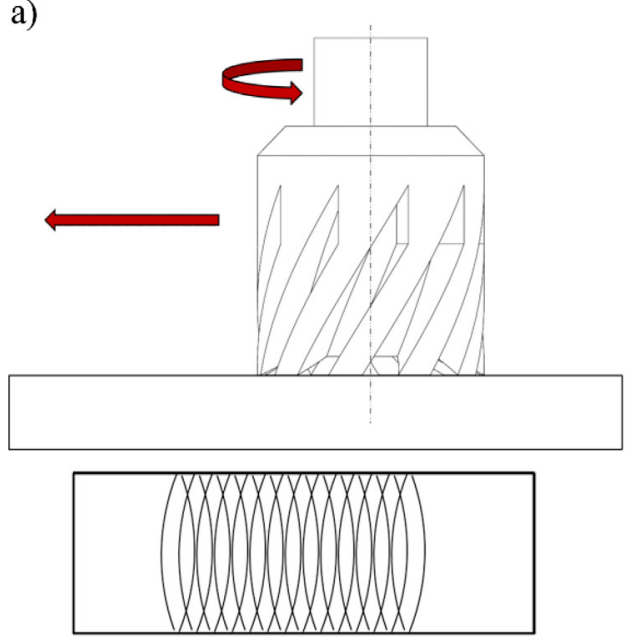

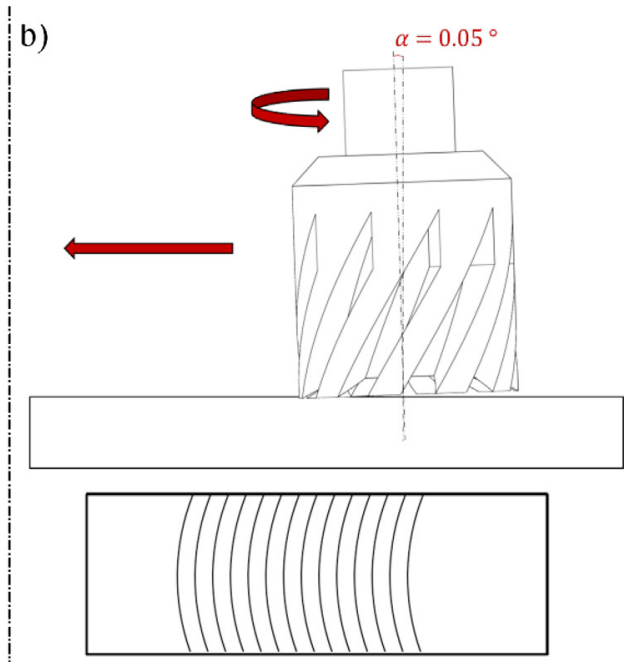

Fig. 4. (a) M4.2 surface state: machining + heeling. (b) M5.5 surface state: machining with tool offset angle of $0.05^{\circ}$. a)

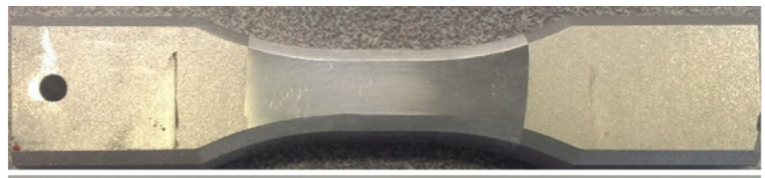

b)

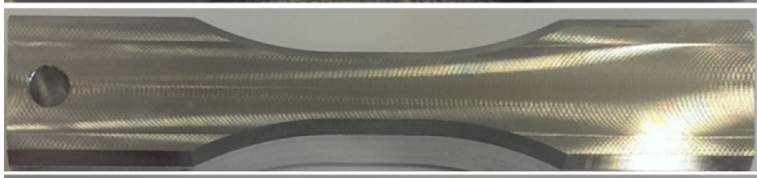

c)

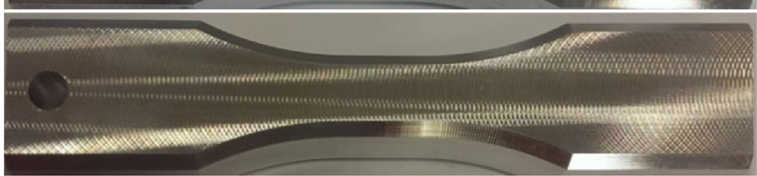

d)

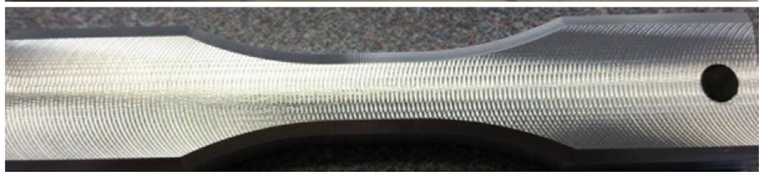

Fig. 5. Specimens with (a) polished, (b) M1.1 (c) M4.2 and (d) M5.5 surface states.

$R_{a}$, arithmetic mean roughness:

$R_{a}=\frac{1}{l_{n}} \int_{0}^{l_{n}}|Z(x)| d x$

$S_{a}$, arithmetic mean height:

$S_{a}=\frac{1}{S} \iint_{S}|Z(x, y)| d x d y$

$S_{q}$, root mean square height:

$S_{q}=\sqrt{\frac{1}{S} \iint_{S}(Z(x, y))^{2} d x d y}$

$S_{z}$, maximum height:

$S_{z}=Z_{\text {max }}+\left|Z_{\text {min }}\right|$

$S_{k u}$, Kurtosis:

$S_{k u}=\frac{1}{S_{q}^{4}} \iint_{S}(Z(x, y))^{4} d x d y$

$S_{v i}$, groove's fluid retention index:

$S_{v i}=\frac{1}{S_{q}} \frac{V_{V}\left(h_{0.8}\right)}{S}$

with $V_{V}\left(h_{0.8}\right)$ : the void volume of the valley section that represents $80 \%$ of the material ratio curve [36], and S: the surface of the measured area.

The repeatability of the surface states produced on the specimens of each batch is verified by the 3D scanning. The standard deviation range of the arithmetic mean height $\bar{S}_{a}$ for each batches is presented in Table 4. In order to simplify the study, specimens of each batch will be considered identical in the following analysis. The values presented in Table 4 are therefore an averaging of all specimens measurements of each batch. The arithmetic mean roughness $R_{a}$ measured along the specimen direction depends on the position of the measured line Fig. 7. In the Table 4 the maximum value of the $R_{a}$ value measured on these different lines is presented.

The batch M1.1, machined under the classic industrial cutting parameters, shows low surface roughness. Resulting machining grooves have a maximum depth of $3 \mu \mathrm{m}$ and around $40 \mu \mathrm{m}$ in width (Fig. 7).

For the M4.2 and M5.5 batches, 2D profiles extracted from 3D scans show that $2 \mathrm{D}$ profile greatly depends on the position of the line considered (Fig. 7). Due to the high value of the feed rate, areas with high difference of altitude are created by the path of the machining tool. The depth of the machining grooves for the M4.2 and M5.5 batches is around $10 \mu \mathrm{m}$, whereas maximum height reaches $29 \mu \mathrm{m}$ for the M4.2 batch and $18 \mu \mathrm{m}$ for the M5.5 batch (Figs. 6 and 7). Even if the M4.2 batch has a higher $R_{a_{\max }}$ than the M5.5 batch, which can be due to the machining conditions (i.e. slight difference in the cutting grooves depth), its $S_{a}$ value is lower (Table 4).

\subsection{Experimental results}

\subsubsection{Fatigue test results}

Fig. 8 shows the results of the fatigue tests in the form of a Wöhler diagram. The well known plateau in fatigue is observed above $3.10^{5}$ cycles. The following analysis will be focused on the High Cycle Fatigue domain and on the level of each plateau for each batch. As observed on the Wöhler curves (Fig. 8) and on the StairCase results (Table 6), the scatter is not pronounced. The StairCase approach allows to estimate a standard deviation of the fatigue strength lower than 5.3 MPa for each batch.

Summarizing the fatigue strength from the different surface states in Table 5, it is clear that the fatigue strength decreases gradually by increasing the surface arithmetic height parameter $S_{a}$.

For the M1.1 surface state, the fatigue strength is $15 \mathrm{MPa}$ (approximately $10 \%$ ) lower than the strength of the polished batch. This means that for the studied aluminium alloy it is necessary to highly degrade the surface roughness to observe a more pronounced effect on fatigue. The M4.2 batch presents a more significant decrease of the fatigue strength with $141 \mathrm{MPa}$. For the M5.5 batch, with a fatigue strength of $119 \mathrm{MPa}$, decrease of the fatigue strength reaches $32 \%$. 


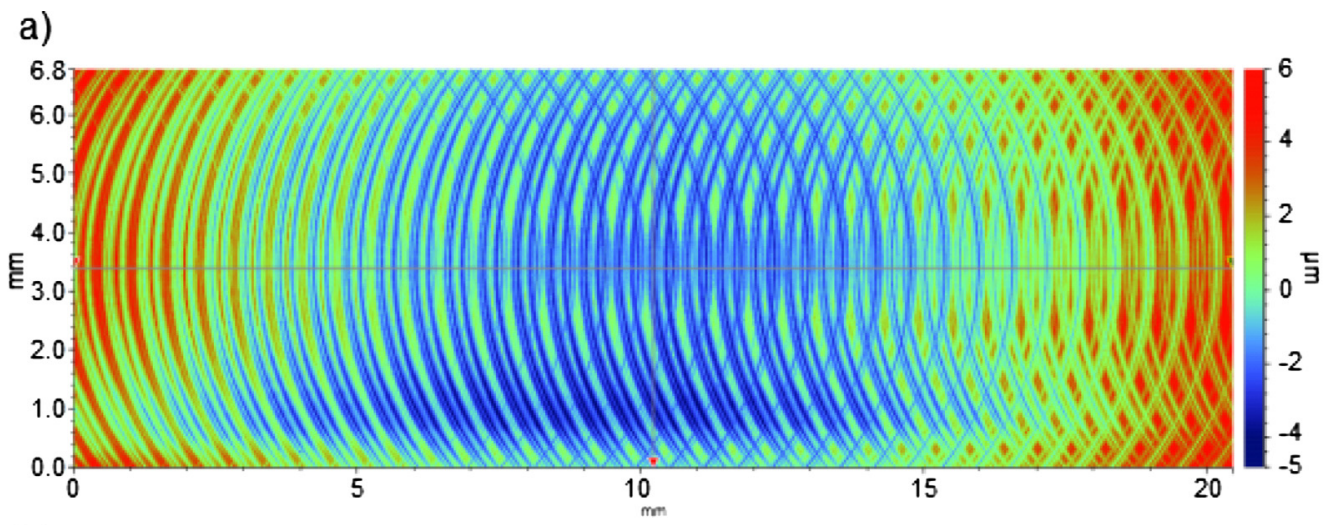

b)

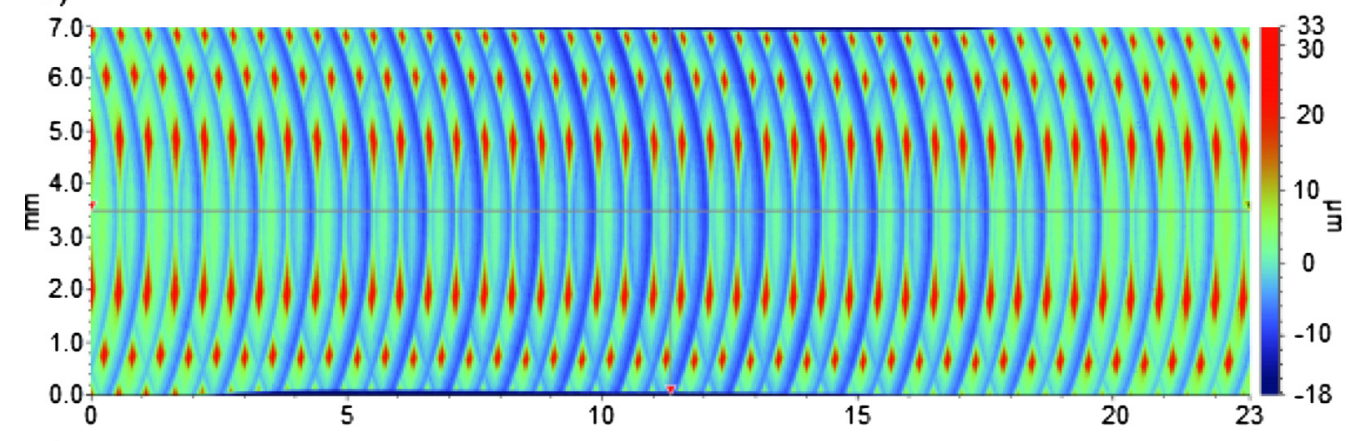

c)

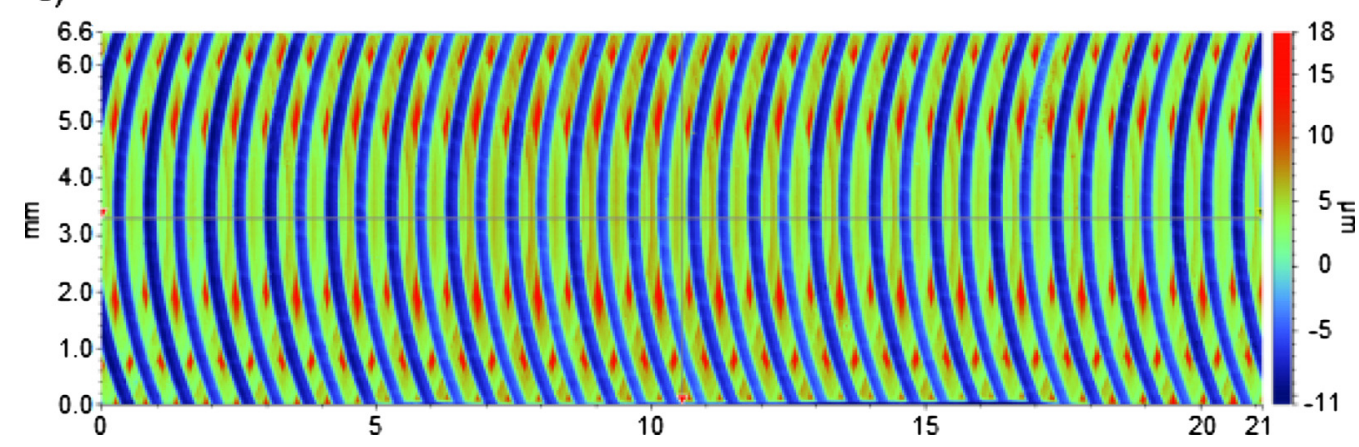

Fig. 6. 3D surface scan of (a) M1.1, (b) M4.2 and (c) M5.5 batch.

\subsubsection{Crack initiation localization}

After all fatigue tests, specimen surfaces are analyzed using optical microscopy. Crack initiation occurs at a single location and coalescence phenomena is not observed. Crack initiation occurred randomly on the gauge length of specimens. SEM observations of the fracture surfaces show that all crack initiations occurred at the upper surface or at few micrometers below the surface of the specimens (see Figs. 9 and 10). For the majority of the specimens and whatever the batch, initiation starts mostly (more than 90 percent of the observed fracture surfaces) from particles (Fig. 10a)) or from $M g Z n_{2}$ precipitates at a nanoscale detected via Energy Dispersive Xray Spectroscopy (EDX) [31]. In a few cases, initiation starts from material matrix (Fig. 10b)). Only the M4.2 batch at low number of cycles (below $2.10^{5}$ cycles) shows systematically initiation without any particles or precipitates.

For the M1.1 surface states, due to the overlap between the multiple grooves of small depth and width, it is difficult to localize the crack initiation sites on the machining grooves. For the M4.2 and the M5.5 batches however, combination of SEM observations and 3D surface scans after fatigue test allows to precisely locate the crack initiation site on the 3D surface scan (Fig. 10). Fig. 10 shows that all crack initiation sites are located at the bottom of the machining grooves.

The machining tool used is a two-tooth tool. For the M4.2 batch, the slight difference in height between these teeth is at the origin of the difference in depth of the order of $2-3 \mu \mathrm{m}$ observed on the 2D profiles (Fig. 10). It can be seen that this small difference in depth is sufficient to locate almost all the crack initiation sites at the bottom of the deepest machining groove (Fig. 10). For the M5.5 batch machining grooves created by the two teeth of the machining tool do not show a significant difference in height. The set of crack initiation sites is therefore randomly located at the bottom of the grooves created by each of the teeth (Fig. 11).

In Fig. 11, the crack initiation sites are positioned on the 3D scan of the surface and compared to the measurement of arithmetic roughness $R_{a}$ performed in the length direction of the specimen and at different positions according to its width. For the two batches M4.2 and M5.5, crack initiation sites coexist in areas of low and high roughness (ie crack initiation sites at $1 \mathrm{~mm}$ and $3.5 \mathrm{~mm}$ across the width of the specimen). Fig. 11 allows to illustrate that the initiation is not systematically located on the lines of higher arithmetic roughness $R_{a}$ and that a fatigue resistance criteria based on this quantity are therefore questionable.

\section{Modeling the AA7050 high cycle fatigue behavior in the presence of different surface states}

The aim of this part is to propose a high cycle fatigue criterion that can estimate the fatigue resistance of machined components whose 

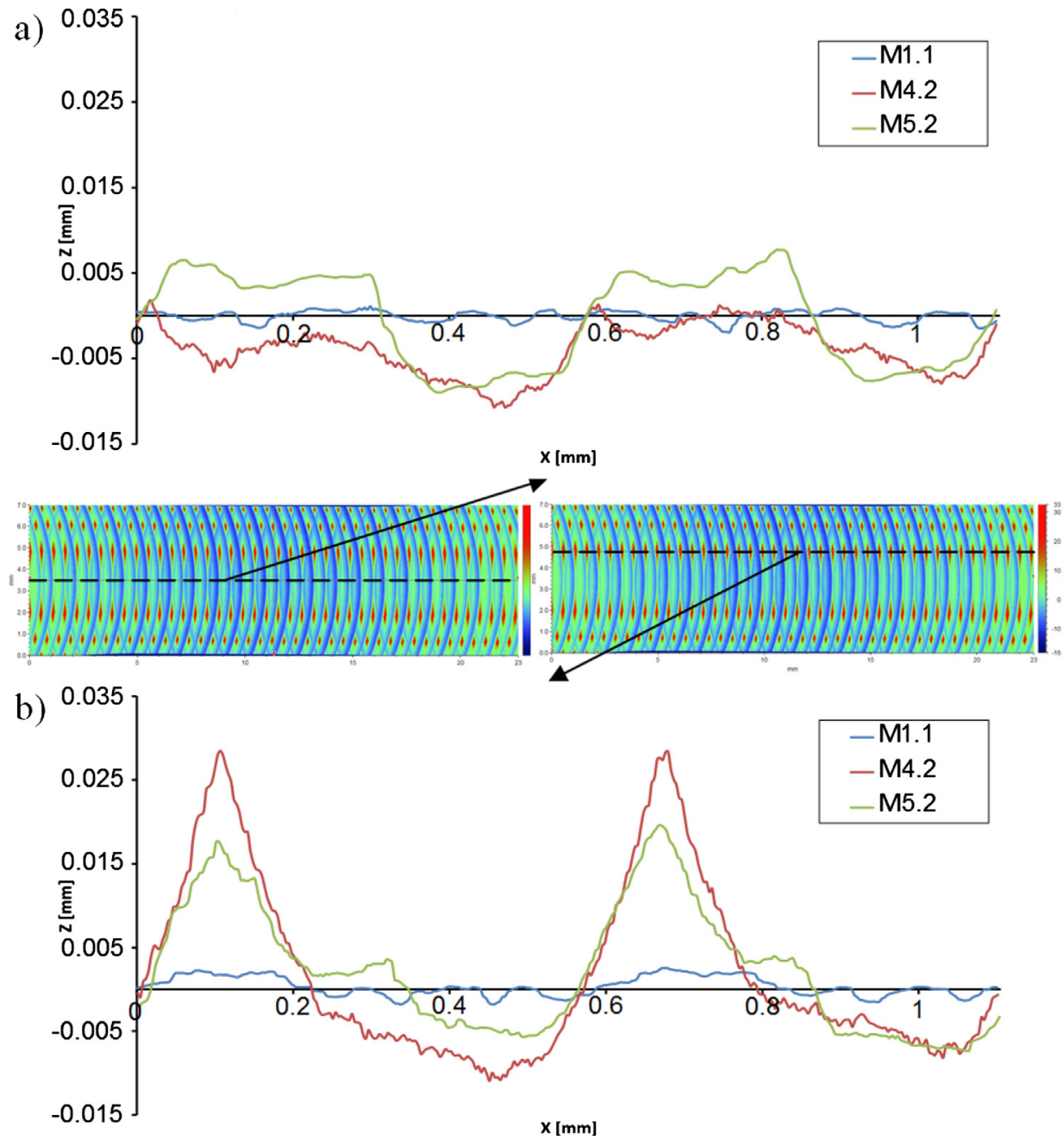

Fig. 7. Machining grooves 2D profiles measured (a) on the middle of the specimen (b) at 1.3 mm from the middle of the specimen.

Table 3

Machining conditions for the AA7050 alloy.

\begin{tabular}{ccccccc}
\hline Surface state & $\mathrm{N}(\mathrm{rpm})$ & $\begin{array}{c}\mathrm{Fz} \\
(\mathrm{mm} / \\
\text { tooth/ } \\
\mathrm{rd})\end{array}$ & $\mathrm{Z}$ (teeth) & $\begin{array}{c}\text { Nose } \\
\text { Radius } \\
(\mathrm{mm})\end{array}$ & $\mathrm{D}(\mathrm{mm})$ & $\begin{array}{c}\text { Orientation } \\
\text { tool/ } \\
\text { workpiece }\end{array}$ \\
\hline M1.1 & 24000 & 0.15 & 2 & 4 & $\emptyset 10$ & $0^{\circ}$ \\
M4.2 & 10000 & 0.55 & 2 & 0.8 & $\emptyset 20$ & $0^{\circ}$ \\
M5.5 & 10000 & 0.55 & 2 & 0.8 & $\emptyset 20$ & $0.05^{\circ}$ \\
\hline
\end{tabular}

surface topology may be periodic or composed of local defects. It is hence necessary to identify surface state parameters that are capable of characterizing the impact of the surface topology on the fatigue behavior. The correlation between different assessments of the stress concentration factors and the fatigue results will then be analyzed.

\subsection{Correlation between fatigue strength and surface condition characteristics}

Among the various parameters used to characterize a surface state, the arithmetic roughness $R_{a}$ is a frequently used parameter in the field of machining. Using the $3 \mathrm{D}$ profilometer, $R_{a}$ measurements were made for each batch of specimens in the direction of loading (Fig. 11). These figures show that $R_{a}$ depends on the position of the measurement across the width of the specimen.

The maximum arithmetic roughness $R_{a_{\max }}$ according to the direction of the specimen was identified for each surface condition by taking different measurements over the width of the specimen. The evolution of the fatigue strength as a function of $R_{a_{\max }}$ is presented in Fig. 12a. A decrease in the fatigue strength is well observed with the increase of $R_{a_{\max }}$. However, the surface state M4.2 having a maximum arithmetic roughness of $9.3 \mu \mathrm{m}$ has a better fatigue strength than the surface state M5.5 having a maximum arithmetic roughness of $7.1 \mu \mathrm{m}$.

Table 4

Surface roughness characteristics of the different surface state batches.

\begin{tabular}{|c|c|c|c|c|c|c|c|}
\hline Surface State & $R_{a \max }(\mu \mathrm{m})$ & $\bar{S}_{a}(\mu \mathrm{m})$ & $\overline{\bar{S}}_{a}(\mu \mathrm{m})$ & $\bar{S}_{q}(\mu \mathrm{m})$ & $\bar{S}_{z}(\mu \mathrm{m})$ & $\bar{S}_{k u}(\mu \mathrm{m})$ & $\bar{S}_{v i}(\mu \mathrm{m})$ \\
\hline P0 & 0.02 & 0.02 & $<0.02$ & 0.05 & 0.42 & 3.55 & 0.12 \\
\hline M1.1 & 1.02 & 1.1 & 0.24 & 1.19 & 7.12 & 2.49 & 0.09 \\
\hline M4.2 & 9.27 & 4.2 & 0.2 & 6.41 & 45.5 & 7.36 & 0.05 \\
\hline M5.5 & 7.1 & 5.5 & 0.76 & 5.74 & 29.1 & 1.94 & 0.04 \\
\hline
\end{tabular}




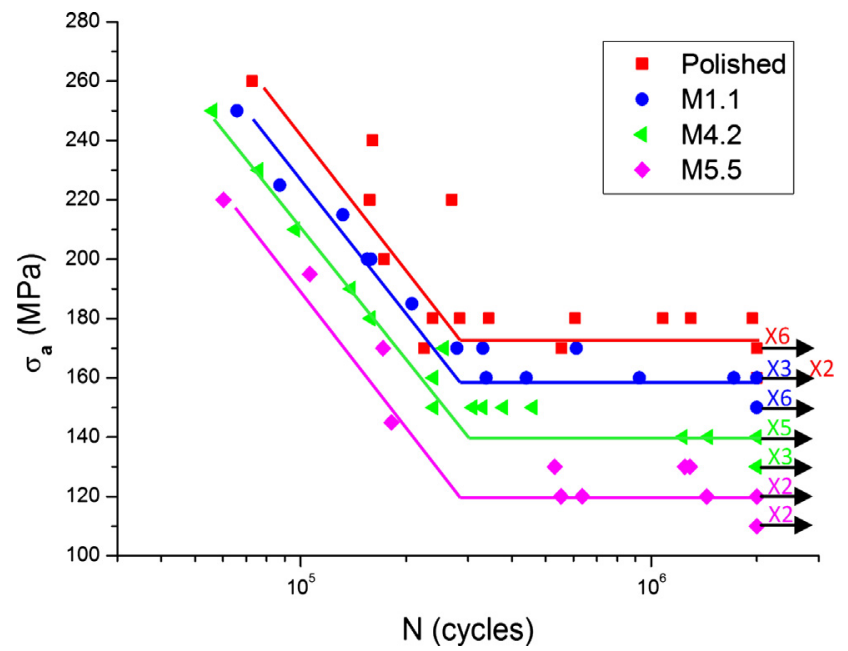

Fig. 8. Wöhler curves for different surface states.

Table 5

Average fatigue strength for the different surface states batches.

\begin{tabular}{ccccc}
\hline Batch & Polished & M1.1 & M4.2 & M5.5 \\
\hline$\sigma_{a}(\mathrm{MPa})$ & 174 & 159 & 141 & 119 \\
\hline
\end{tabular}

In order to take into account the whole surface topology and not the sole roughness over a line, the arithmetic mean height of surface $S_{a}$ was also measured for each batch. Fig. 12b shows that the fatigue strength decreases gradually as $S_{a}$ increases. $S_{a}$ appears therefore to be a more convenient parameter for characterizing the impact of surface topology on fatigue.

The same approach to search for a possible correlation between surface state parameters and fatigue strength has been applied to all the usual surface condition criteria (Sq, Sz, Skewness Ssk and Sku). None of these criteria seems to show a clear link between the fatigue strength and the surface topography of the different tested batches. For example, Fig. $12 \mathrm{c}$ and $12 \mathrm{~d}$ illustrate the evolution of the fatigue strength as a function of the Sq and Sz surface parameters that are used to characterize the impact of the surface condition on the fatigue behavior by some authors $[3,14,37]$ and for which the correlation is not direct. In the same way as for the $R_{a_{\max }}$ parameter, the $S_{z}$ parameter, which takes into account the lowest positions in the surface grooves, and the $S_{q}$ parameter, which describes the standard deviation of the surface roughness [36], are higher for the batch M4.2 than for the batch M5.5.
In conclusion, for the investigated surface states, the obtained results show that the surface parameter $S_{a}$ is the best suited parameter to capture the effect of the surface topology on the fatigue behavior of the end milled parts.

\subsection{Literature criteria estimating the impact of surface condition on the fatigue strength}

This paragraph presents the literature criteria that correlate the fatigue strength with the surface topography [15] or with the stress concentration generated by the surface topography (mainly located at the valley of the grooves and described by a peak value of the stress, generated as a result of a nominal loading, often applied upon the component in a perpendicular direction to the grooves) [11-14].

The Murakami criterion [15] is one of the most used criteria for predicting the impact of surface or internal defects on the HCF behavior. Murakami also adapted his criterion to machined surface conditions. The defect size parameter noted $\sqrt{\text { area }}$ is in this case estimated as a function of the depth and the spacing between successive machining grooves [15]:

$\sqrt{\text { area }}=\left(\frac{F\left(\frac{a}{2 b}\right)}{0.65}\right)^{2} a$

with $a$ the depth of the groove, $2 b$ the spacing between 2 successive grooves and $F\left(\frac{a}{2 b}\right)$ is a geometric correction factor which depends on the parameters $a$ and $2 b$ (see Fig. 13).

Let's recall that the fatigue strength is predicted by the Murakami criterion through the equation:

$\sigma_{D}=\frac{1.43\left(H_{v}+120\right)}{(\sqrt{\text { area }})^{1 / 6}}$

with $H_{v}$ the Vickers hardness of the material.

Since the Murakami criterion is based on a roughness profile considered over a line, the calculated predictions will be based on the line where the defect size $\sqrt{\text { area }}$ (and hence the depth value a) is maximal. The fatigue resistance of the polished batch PO is not predicted with the Murakami criterion but considered as the experiment fatigue resistance found for this batch $(174 \mathrm{MPa})$. Fig. 15 shows that the Murakami criterion does not predict successfully the fatigue strength of the machined surface states. Considering the machining grooves as "ideal" defects having the same projected area according to the loading direction via the $\sqrt{\text { area }}$ parameter does not make it possible to estimate the fatigue strength of the different tested batches.

In the literature, there is a number of empirical fatigue criteria

Table 6

Test history for StairCase tested specimens.

\begin{tabular}{|c|c|c|c|c|c|c|c|c|c|c|c|c|c|c|c|c|}
\hline \multirow{2}{*}{$\begin{array}{l}\text { Surface } \\
\text { State }\end{array}$} & \multirow{2}{*}{$\begin{array}{c}\text { Nominal Stress } \\
\text { Amplitude (MPa) }\end{array}$} & \multicolumn{15}{|c|}{ Specimen Number } \\
\hline & & 1 & 2 & 3 & 4 & 5 & 6 & 7 & 8 & 9 & 10 & 11 & 12 & 13 & 14 & 15 \\
\hline \multirow[t]{3}{*}{ P0 } & 180 & & & $\mathrm{X}$ & & $\mathrm{X}$ & & $\mathrm{X}$ & & $\mathrm{X}$ & & & & $\mathrm{X}$ & & $\mathrm{X}$ \\
\hline & 170 & & $\mathrm{O}$ & & $\mathrm{O}$ & & $\mathrm{O}$ & & $\mathrm{O}$ & & $\mathrm{X}$ & & $\mathrm{O}$ & & $\mathrm{O}$ & \\
\hline & 160 & $\mathrm{O}$ & & & & & & & & & & $\mathrm{O}$ & & & & \\
\hline \multirow[t]{3}{*}{ M1.1 } & 170 & & & & & & & $\mathrm{X}$ & & $\mathrm{X}$ & & & & $\mathrm{X}$ & & \\
\hline & 160 & & $\mathrm{X}$ & & $\mathrm{X}$ & & $\mathrm{O}$ & & $\mathrm{O}$ & & $\mathrm{X}$ & & $\mathrm{O}$ & & $\mathrm{X}$ & \\
\hline & 150 & $\mathrm{O}$ & & $\mathrm{O}$ & & $\mathrm{O}$ & & & & & & $\mathrm{O}$ & & & & $\mathrm{O}$ \\
\hline \multirow[t]{3}{*}{ M4.2 } & 150 & & $\mathrm{X}$ & & & & & & $\mathrm{X}$ & & $\mathrm{X}$ & & $\mathrm{X}$ & & & \\
\hline & 140 & $\mathrm{O}$ & & $\mathrm{X}$ & & $\mathrm{X}$ & & $\mathrm{O}$ & & $\mathrm{O}$ & & $\mathrm{O}$ & & $\mathrm{X}$ & & $\mathrm{O}$ \\
\hline & 130 & & & & $\mathrm{O}$ & & $\mathrm{O}$ & & & & & & & & $\mathrm{O}$ & \\
\hline \multirow[t]{3}{*}{ M5.5 } & 130 & & $\mathrm{X}$ & & & & $\mathrm{X}$ & & & & & & & & & \\
\hline & 120 & $\mathrm{O}$ & & $\mathrm{X}$ & & $\mathrm{O}$ & & $\mathrm{X}$ & & $\mathrm{X}$ & & & & & & \\
\hline & 110 & & & & $\mathrm{O}$ & & & & $\mathrm{O}$ & & $\mathrm{O}$ & & & & & \\
\hline
\end{tabular}


a)

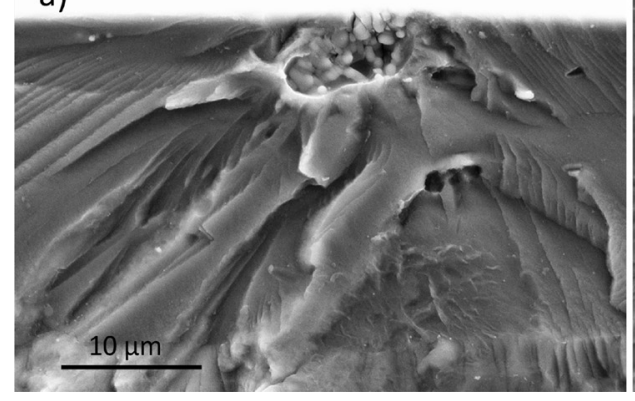

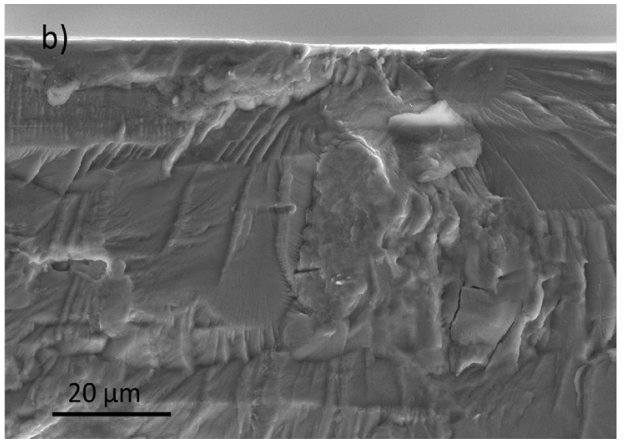

Fig. 9. Failure surface, initiation start from (a) particle (b) material matrix. based on the estimation of the stress concentration generated by the surface topology measured over a line. Table 7 contains the expressions of the 3 analytical stress concentration estimations studied in this section.

For these expressions, $a$ is the depth of the groove, $\rho$ the radius at the bottom of the defect (machining groove), $2 b$ the distance between two successive grooves, $R_{z}$ the average maximum height of the measured profile, $R_{t}$ the maximum height of the measured profile and $n$ a parameter equal to 2 in case of tensile stress loading. For a real profile, the identification of the depth $a$ and the radius of the groove $\rho$ is not easy. As shown in Fig. 14, the radius of the red circle for example describes the machining groove in its totality, the stress concentration factor generated for this radius via the Inglis expression is 1,2 . The stress concentration factor generated by considering the radius at a
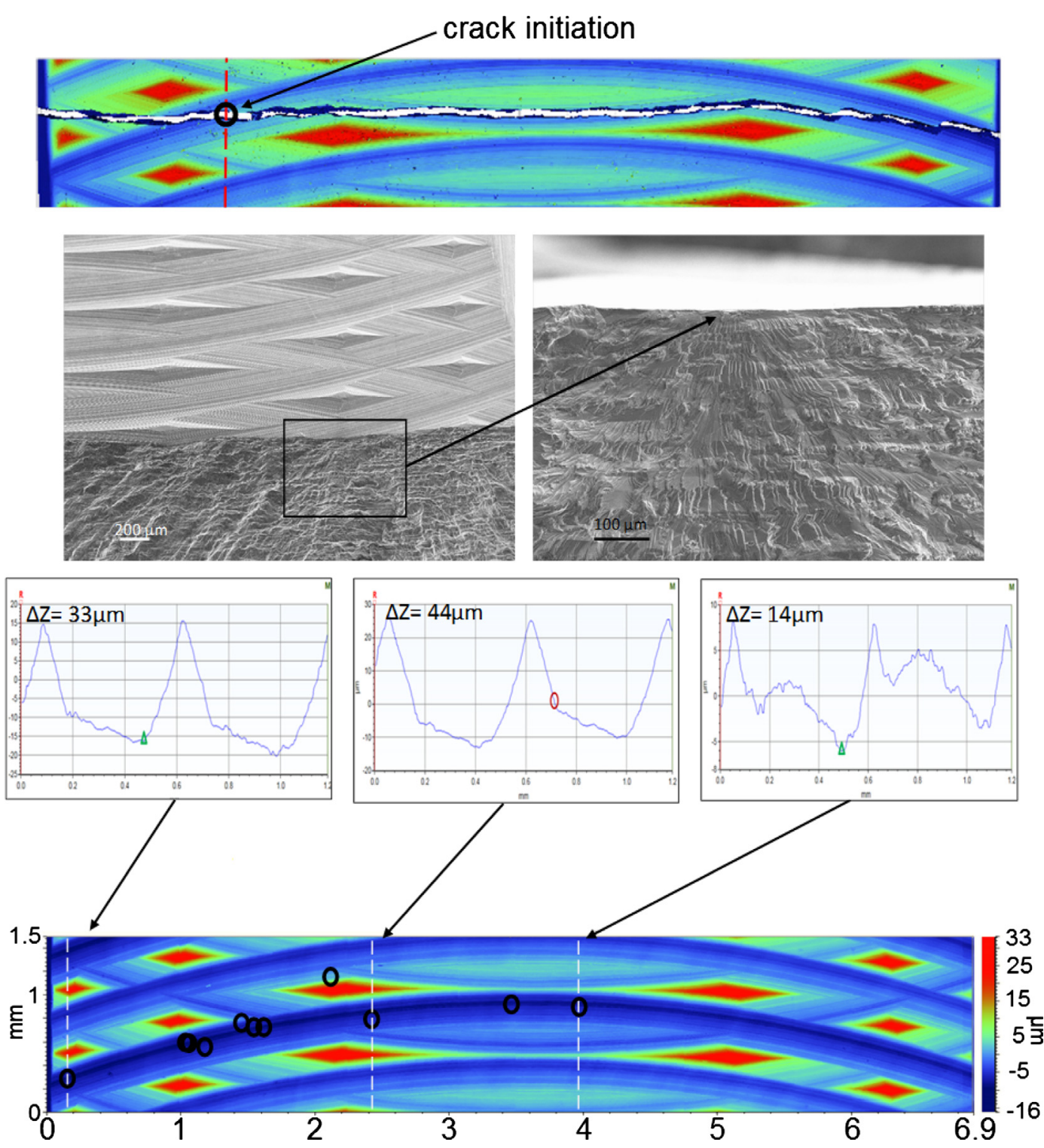

Fig. 10. Localization process of crack initiation sites for the M4.2 surface state. 

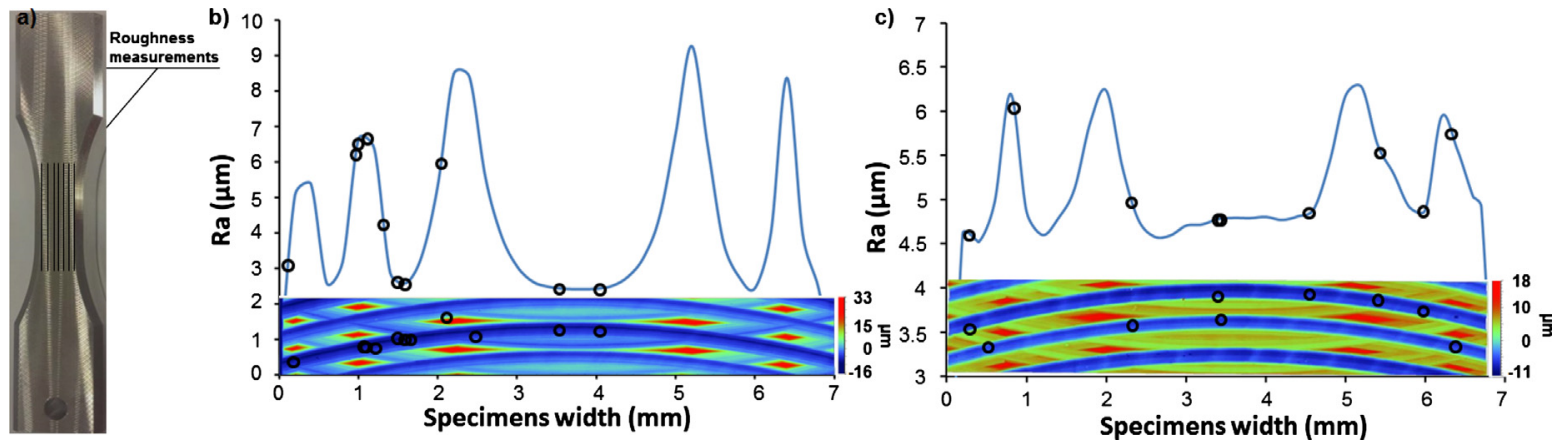

Fig. 11. Comparison between crack initiation sites location and arithmetic roughness $R_{a}$ (a) for (b) M4.2 and (c) M5.5 surface state.

more local scale described by the green circle is 2 . The estimation of the stress concentration factor via the different approaches presented in Table 7 is therefore very dependent on the observation scale and the measurement of the radius and the depth of the groove. Fig. 14 illustrates, in the case of the M4.2 batch, the important error that can be generated by the choice of the observation scale.

For the Neuber and Arola estimations, the profile along the axis of the specimen maximizing the estimated stress concentration factor is used. The depth of the groove is considered equal to the distance between the top and the bottom of the groove and $\rho$ is measured at the local scale (example of the green radius in Fig. 14). Figs. 14 and 15 show that, regardless of the approach considered (Inglis, Neuber or Arola), for the different batches, the fatigue strength does not seem to correlate with local stress concentration estimations.

As the estimation of the stress concentration factor in the loading direction via the measurement of a $2 \mathrm{D}$ profile has shown its limits, Souto-Lebel [14] proposed a criterion based on surface parameters. This criterion determines, via measurements made over the entire gauge length surface of the specimens, an effective fatigue stress concentration factor presented in Table 7. In our case, the material parameter $a_{c}$ that minimizes the error predictions is $10 \mu \mathrm{m}$. Even though surface parameters are considered, the predictions made with the Souto-Lebel criterion do not seem to correlate with the fatigue limits obtained for the different tested batches (Fig. 15).

In conclusion, applying analytical approaches [11-15] that try to
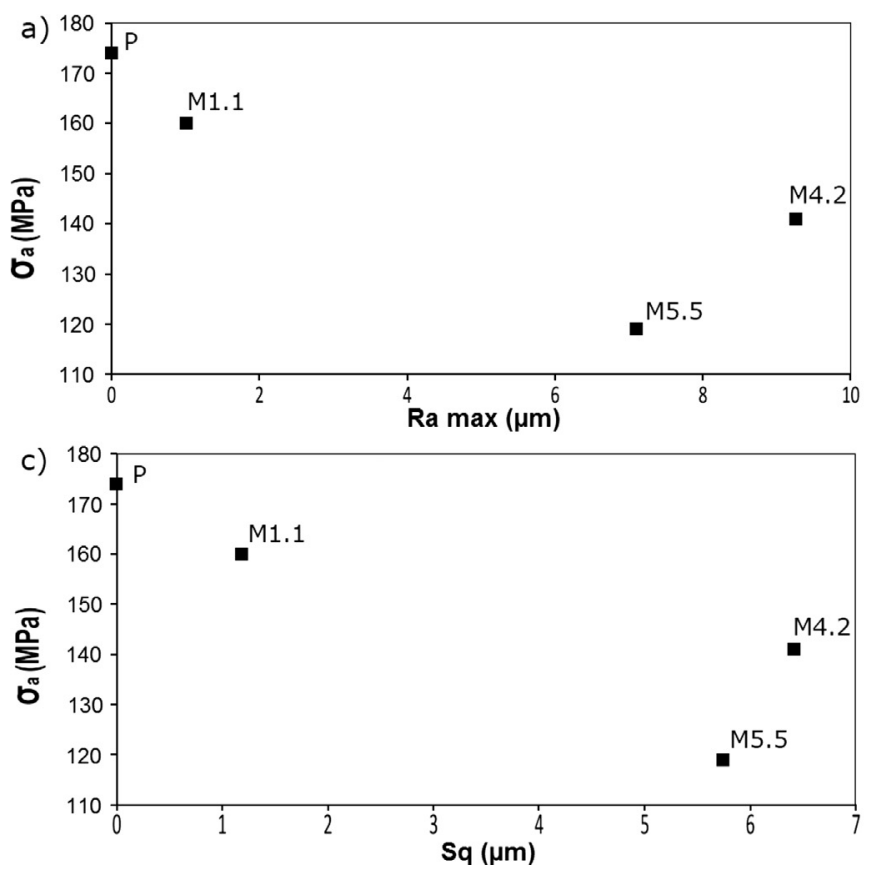

estimate the stress concentration factors from 2D or 3D profiles measurements on machined surface states is not easy due to the complex geometries of the real profiles. This complexity can not be approximated by a geometry with a single notch. Even though this type of approach is applicable to turned parts, its use on machined parts by end milling process is questionable.

In order to estimate the stress field generated by the complex surface topology resulting from the end machining process, a finite element calculation based on the 3D scan of the real surface can be used. Being able to have the stress field generated by a machined surface state is a first step towards the development of a HCF design approach. It is also necessary to use a proper fatigue criterion capable of accounting for the gradient and size effect.

\section{A probabilistic fatigue criterion to account for the size effect}

This chapter aims at presenting a probabilistic approach built to account in a more efficient way for the roughness due to end milling.

Previous work of the same authors carried out on specimens containing different sizes and numbers of simplified geometry defects has shown that Aluminum AA7050 is very sensitive to the statistical size effect [31]. The results obtained are summarized on a Kitagawa-Takahashi diagram presented in Fig. 17, in which it can observed that:

- Fatigue limit decreases gradually when increasing defect size
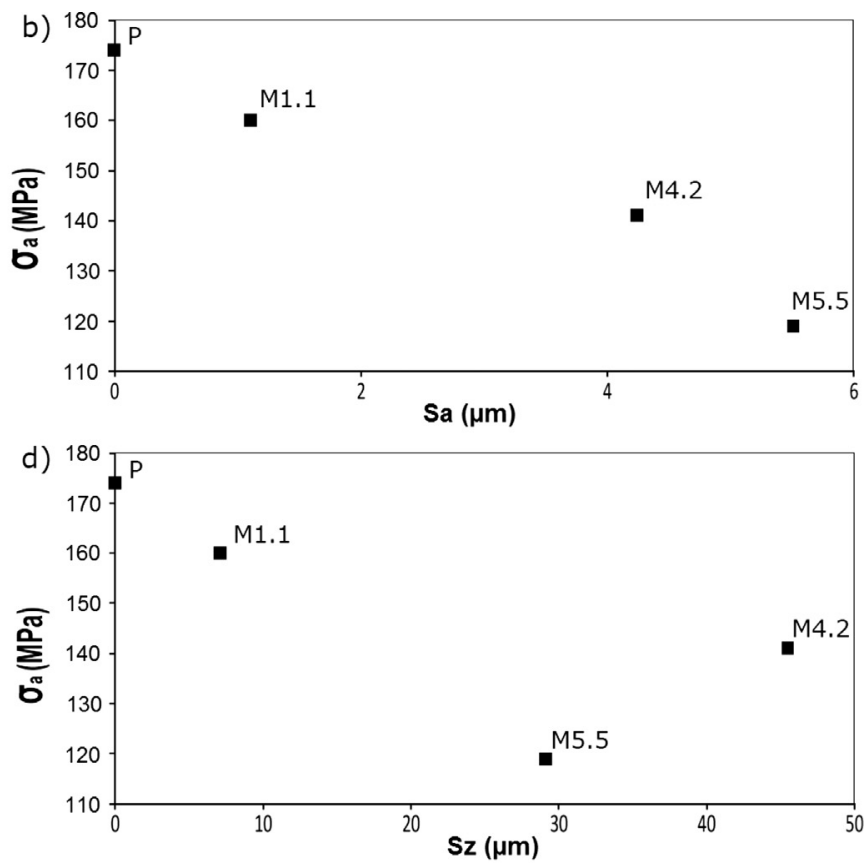

Fig. 12. Evolution of the fatigue strength as a function of (a) $R_{a_{\max }}$, (b) $S_{a}$, (c) $S_{q}$ and (d) $S_{z}$. 
a)

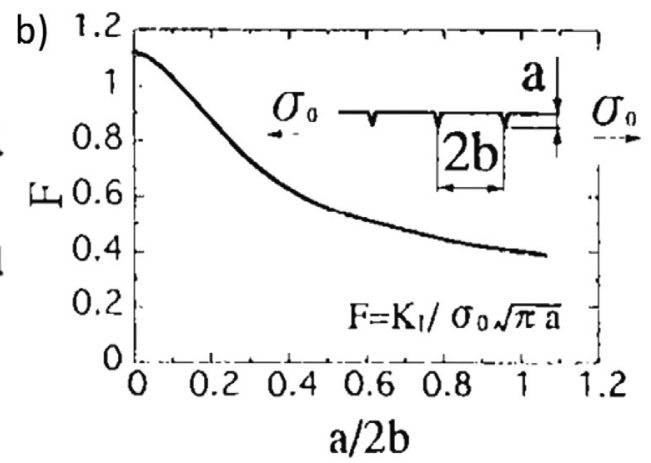

Fig. 13. (a) Simulation of surface defects with a succession of grooves, (b) KI factor for periodic surface grooves [15].

\section{Table 7}

Expressions of the stress concentration factors $K_{t}$ proposed by Inglis [11], Neuber [13], Arola [12] and of the fatigue stress concentration factor $K_{f}$ proposed by Souto-Lebel [14].

\begin{tabular}{cccc}
\hline$K_{t}$ Inglis & $K_{t}$ Neuber & $K_{t}$ Arola & $K_{f}$ Souto-Lebel \\
\hline $1+2 \sqrt{\frac{a}{\rho}}$ & $1+n \sqrt{\frac{2 b}{a} \frac{R_{z}}{\rho}}$ & $1+n \frac{R_{a}}{\rho} \frac{R_{t}}{R_{z}}$ & $1+S_{v i} S_{k u} \frac{S_{q}}{a_{c}}$ \\
\hline
\end{tabular}

- An increase in the number of hemispherical defects of exactly the same size (from 1 to 22) causes the fatigue strength to decrease significantly.

When turning to the case of grooves due to machining, there is every reason to think that the number and the length of those particular defects can affect the fatigue strength for the same reasons as for the defects of simplified geometry.

As the statistical size effect seems to be the reason why the fatigue
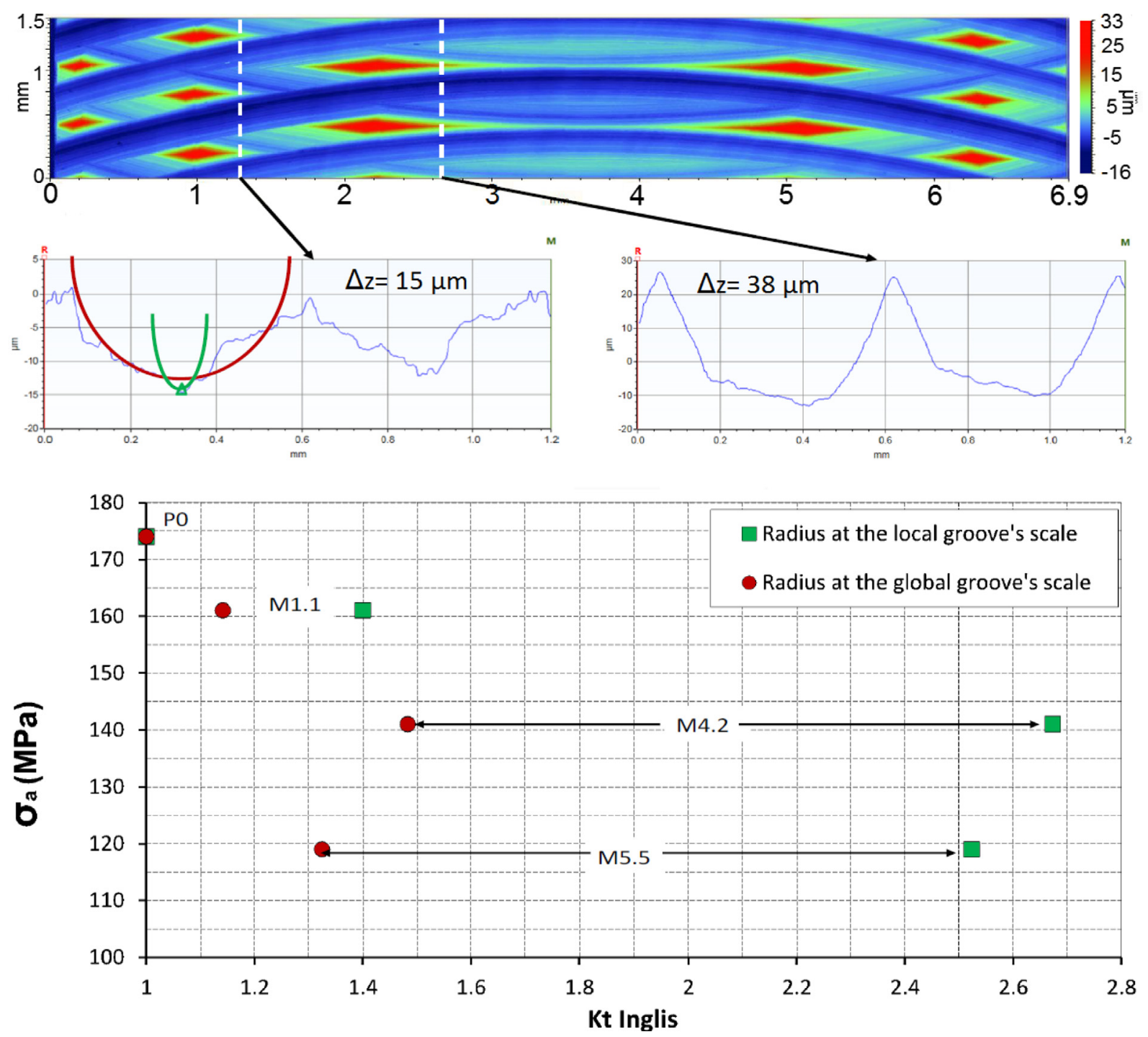

Fig. 14. Effect of the $\rho$ parameter on stress concentration prediction for a machined surface. 

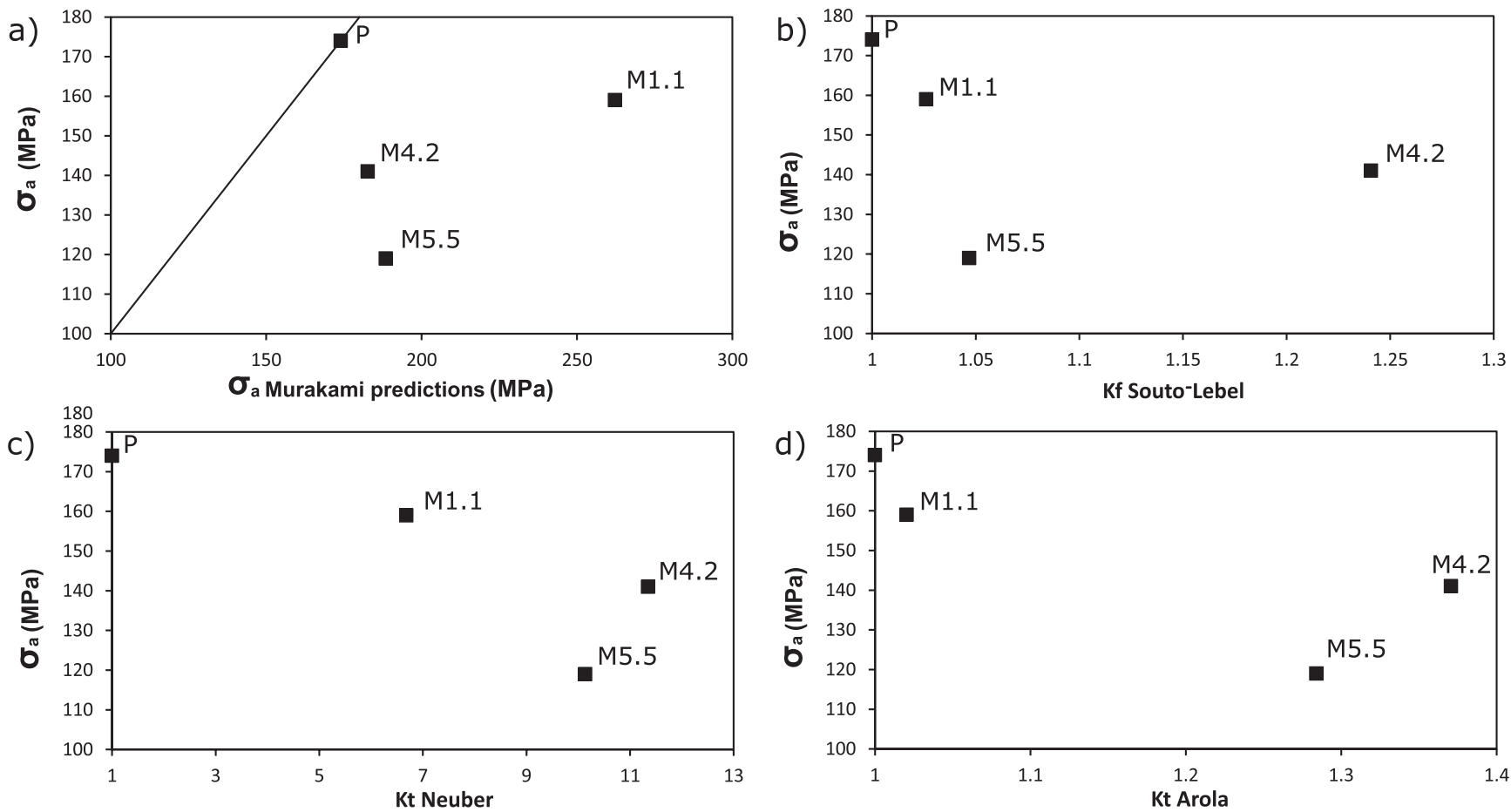

Fig. 15. Evolution of the fatigue strength as a function of the predictions according to the (a) Murakami, (b) Souto-Lebel, (c) Neuber and (d) Arola approach.

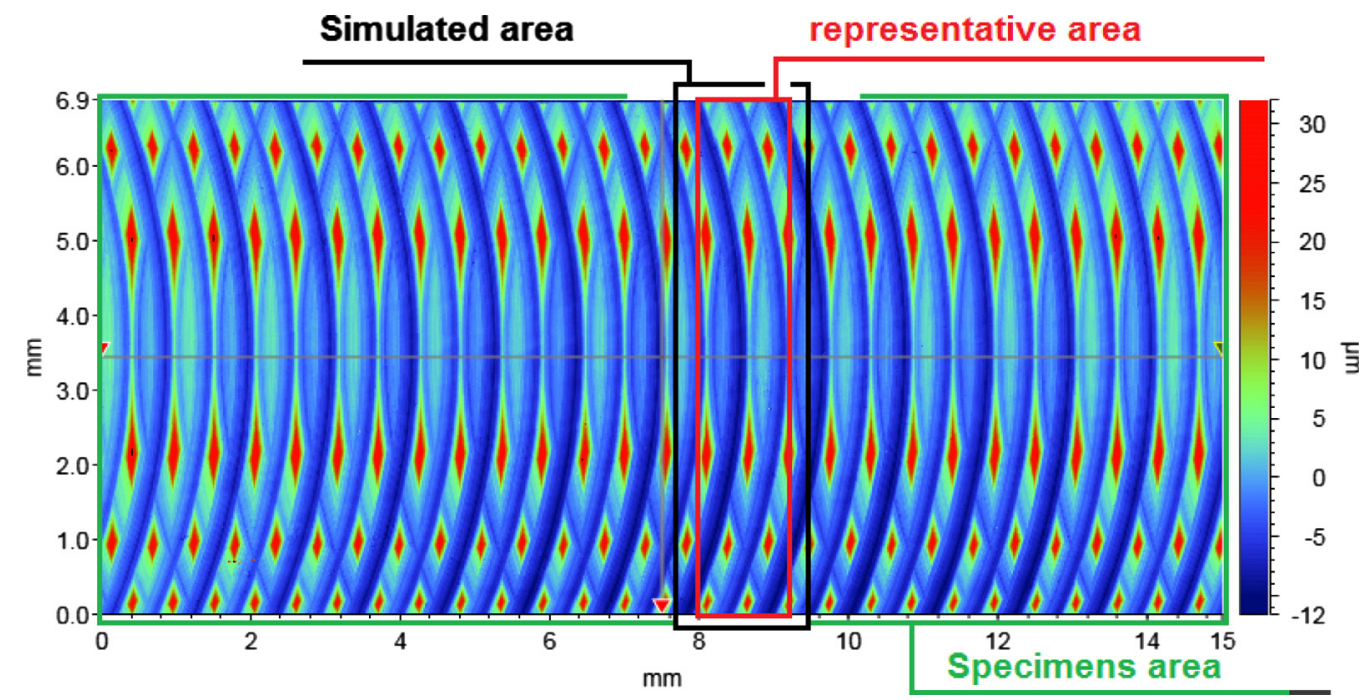

Fig. 16. M4.2 surface scan showing the different surface area used for fatigue analysis.

Table 8

Parameters of the surface and volume probabilistic approaches as defined in [31].

\begin{tabular}{cccc}
\hline Parameter & $d *(\mu \mathrm{m})$ & $m$ & $\sigma_{0}(\mathrm{MPa})$ \\
\hline Surface approach & - & 17 & 240 \\
Volume approach & 50 & 22 & 226 \\
\hline
\end{tabular}

strength is affected, it is proposed to apply a probabilistic approach based on the weakest link concept allowing to integrate the entire stress field at the surface and to consider the impact of the size of the highly stressed area on the fatigue strength.

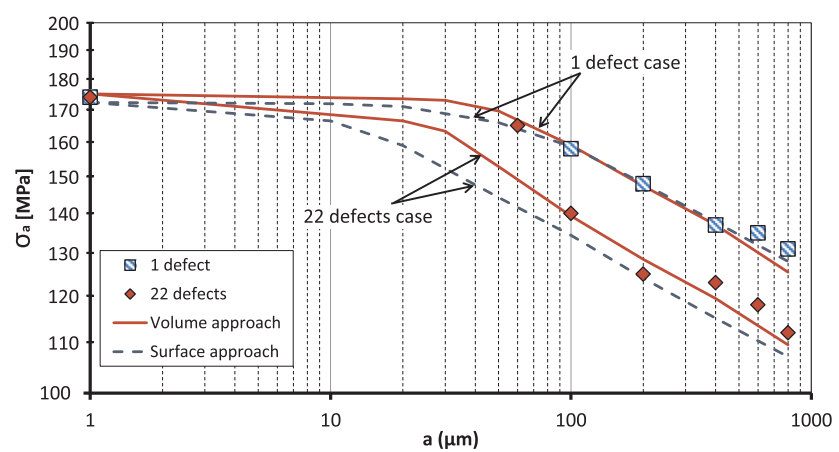

Fig. 17. Predictions of fatigue behaviour using a surface and a volume approach in the case of polished specimens with different size and number of hemispherical defects [31]. 


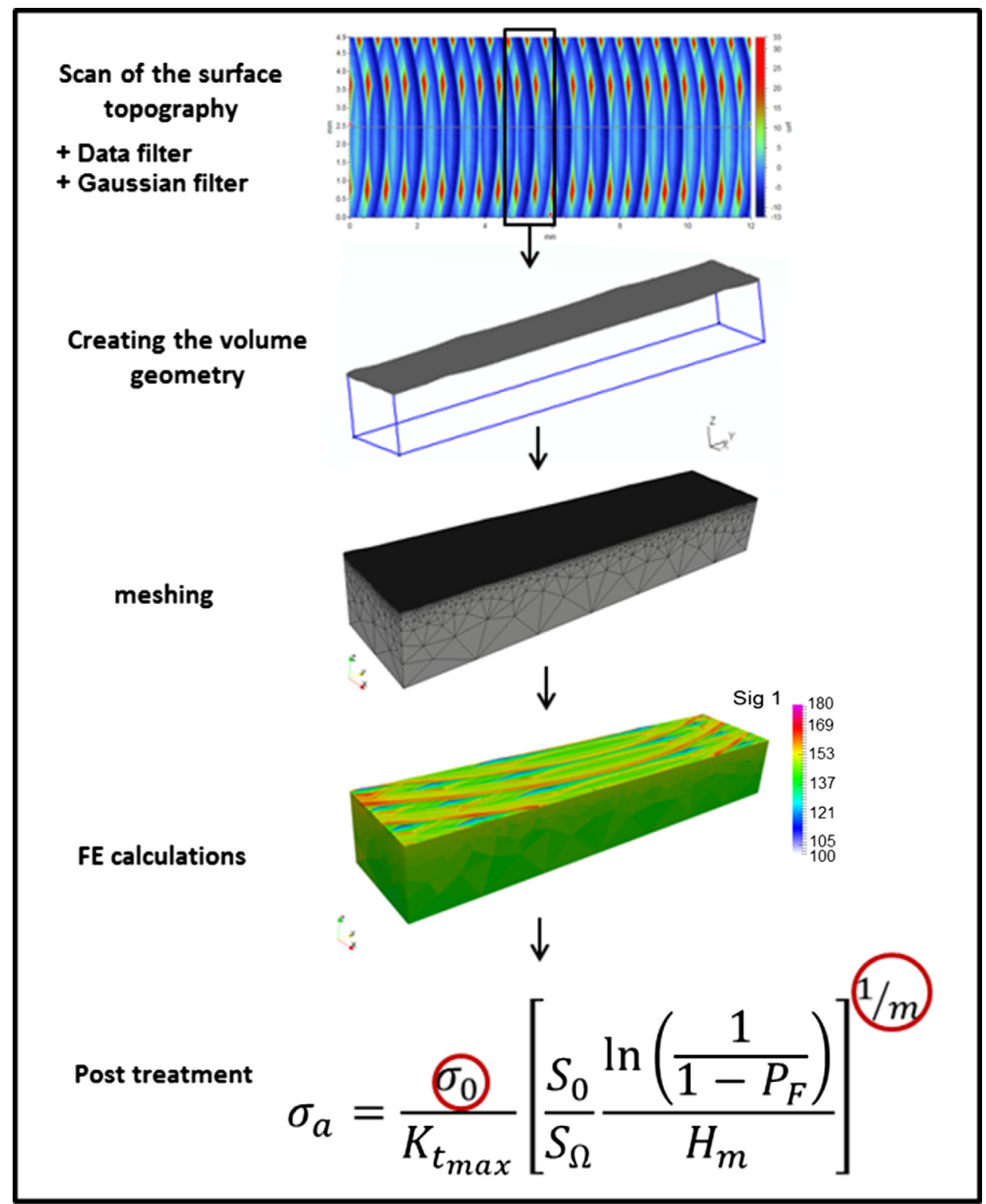

Fig. 18. Steps followed for the numerical simulation.

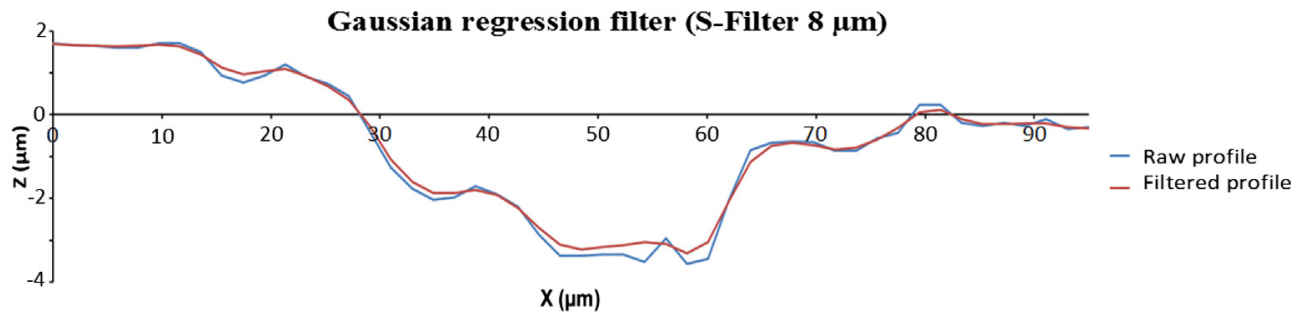

Fig. 19. Illustration of the impact of the gaussian filter on the raw profile.

\subsection{Probabilistic framework}

This section is devoted to the development of a HCF criterion able to predict the effect of surface defects on fatigue. The proposed model is defined, as is the case of most fatigue criteria, by an equivalent mechanical quantity (i.e. stress, strain, energy, etc.), which is compared to a threshold quantity, for a given number of cycles. In the following, for convenience, stress quantities will be employed. Crack initiation is therefore predicted once the equivalent stress is greater than or equal to the threshold stress value. This condition for crack initiation is defined by:

$\sigma_{e q} \geqslant \sigma_{t h}$

Note that in this section, the maximum principal stress amplitude is considered as responsible for crack initiation. Even though the maximum principal stress criterion is not well suited to model the fatigue behavior of ductile material, this criterion is chosen for its simplicity and is used below to explain the proposed methodology. It has been verified that the use of other equivalent stresses leads to very close predictions (see Section 5.2). 


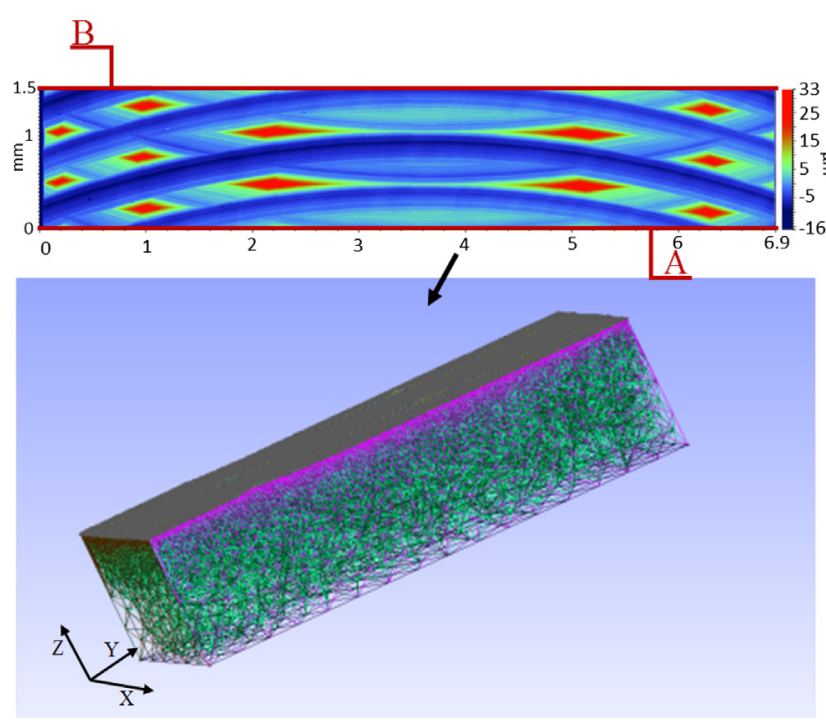

Fig. 20. FE model based on the actual surface topography of machined specimen.

In order to take into account the inherent stochastic nature of the fatigue phenomenon it is proposed, as part of the modelling framework, to use a two parameter Weibull distribution $[38,23]$ to describe the threshold stress $\sigma_{t h}$.

The choice to use a two parameter Weibull distribution then makes it possible to define the probability of crack initiation. Eq. (10) shows the probability density function of the threshold stress.

$f_{0}\left(\sigma_{t h}\right)=\frac{m}{\sigma_{0}}\left(\frac{\sigma_{t h}}{\sigma_{0}}\right)^{m-1} \exp \left\{-\left(\frac{\sigma_{t h}}{\sigma_{0}}\right)^{m}\right\}$

where $\sigma_{0}$ is the scale parameter and $m$ is the shape parameter (or the Weibull exponent) used to reflect the scatter associated with the threshold stress and hence the fatigue strength.

The probability of microcrack initiation corresponds to the probability of finding a threshold stress $\sigma_{t h}$ that is less than the applied equivalent stress $\sigma_{e q}$ (e.g: maximum principal stress). This can be expressed as:

$P_{F_{0}}=\left(\sigma_{t h}<\sigma_{e q}\right)=\int_{0}^{\sigma_{e q}} f_{0}\left(\sigma_{t h}\right) d \sigma_{t h}$

Using the equation of Weibull's distribution function, the integration allows to express the failure probability as follows:

$P_{F_{0}}=1-\exp \left[-\left(\frac{\sigma_{e q}}{\sigma_{0}}\right)^{m}\right]$

To obtain the probability of crack initiation for the complete structure $P_{F}$, the weakest link theory is used [22]. The probability of survival of the structure $\left(1-P_{F}\right)$ is defined as the product of the survival probabilities of each elementary volume or surface. In this work it will be firstly assumed that crack initiation is essentially a surface phenomenon, where the quantity $S_{0}$ corresponds to a reference surface area of $1 \mathrm{~mm}^{2}$ and $S_{\Omega}$ is the total surface area of the domain $\Omega$ corresponding to the specimen (see Fig. 16).

$1-P_{F}=\prod_{S_{\Omega}}\left(1-P_{F_{0}}\right)$

Hence the probability of survival of the complete structure is given by:

$P_{F}=1-\exp \left[-\frac{1}{S_{0}} \int_{S_{\Omega}}\left(\frac{\sigma_{e q}}{\sigma_{0}}\right)^{m} d S\right]$

Introducing the surface stress heterogeneity factor on the component surface $H_{m s}[39]$ :

$H_{m s}=\frac{1}{S_{\Omega}} \int_{S_{\Omega}}\left(\frac{\sigma_{e q}}{\sigma_{\max }}\right)^{m} d S$

with $\sigma_{\max }$ the maximum equivalent stress on the component surface:

$\sigma_{\max }=\max _{S_{\Omega}}\left(\sigma_{e q}\right)$

The expression for the failure probability of the total structure becomes:

$P_{F}=1-\exp \left[-\frac{S_{\Omega}}{S_{0}} H_{m s}\left(\frac{\sigma_{\max }}{\sigma_{0}}\right)^{m}\right]$

In order to simplify the expression and to make a link with the high cycle fatigue strength, the macroscopic fatigue strength $\sigma_{a}$ can be expressed via the following expression:

$\sigma_{a}=\frac{\sigma_{0}}{K_{t_{\max }}}\left[\frac{S_{0}}{S_{\Omega}} \frac{\ln \left(\frac{1}{1-P_{F}}\right)}{H_{m s}}\right]^{1 / m}$

where $K_{t_{\max }}$ is the maximal equivalent stress concentration factor which corresponds to the maximal equivalent stress divided by the nominal applied stress.

$K_{t_{\max }}=\frac{\sigma_{\max }}{\sigma_{\text {applied }}}$

In the case of polished specimen and a simple uniaxial loading, the surface stress heterogeneity factor $H_{m s}$ could be easily obtained by an analytical calculation [39]. In the case of the machined surface states, the surface stress field is more complex and numerical finite element simulations are necessary to assess this quantity.

The proposed criterion is a 2 parameters model with $m$ and $\sigma_{0}$ that have been identified in a previous work [31]. To identify these parameters, the criterion has been applied on polished specimens with different sizes and numbers of hemispherical defects (Table 8) under a surface and a volume formulations.

For the volume approach, the maximum principal stress distribution is considered in a domain consisting of a volume $V_{\Omega}$ with a constant depth $d^{*}$ from the free surface $S_{\Omega}$.

Hence, the stress heterogeneity factor $H_{m v}$ is expressed as follows:

$H_{m v}=\frac{1}{V_{\Omega}} \int_{V_{\Omega}}\left(\frac{\sigma_{e q}}{\sigma_{\max }}\right)^{m} d V$

where $\sigma_{\max }$, the maximum equivalent stress on the component volume, reads:

$\sigma_{\max }=\max _{V_{\Omega}}\left(\sigma_{e q}\right)$

In the same way as for the surface approach, fatigue strength can hence be predicted as:

$\sigma_{a}=\frac{\sigma_{0}}{K_{t_{\max }}}\left[\frac{V_{0}}{V_{\Omega}} \frac{\ln \left(\frac{1}{1-P_{F}}\right)}{H_{m v}}\right]^{1 / m}$

where $V_{0}$ represents the reference volume.

For a value of $d^{*}$ equal to $50 \mu \mathrm{m}$, the two parameters $m$ and $\sigma_{0}$ are identified in [31] and are presented in Table 8. Fatigue strength predictions via the volume approach are also presented in Fig. 17 [31]. Better correlation with the experimental results is found via the volume approach where the fatigue strength in case of 22 defects of $\emptyset 60 \mu \mathrm{m}$ is predicted with less error (9\%). 


\section{a) M1.1}
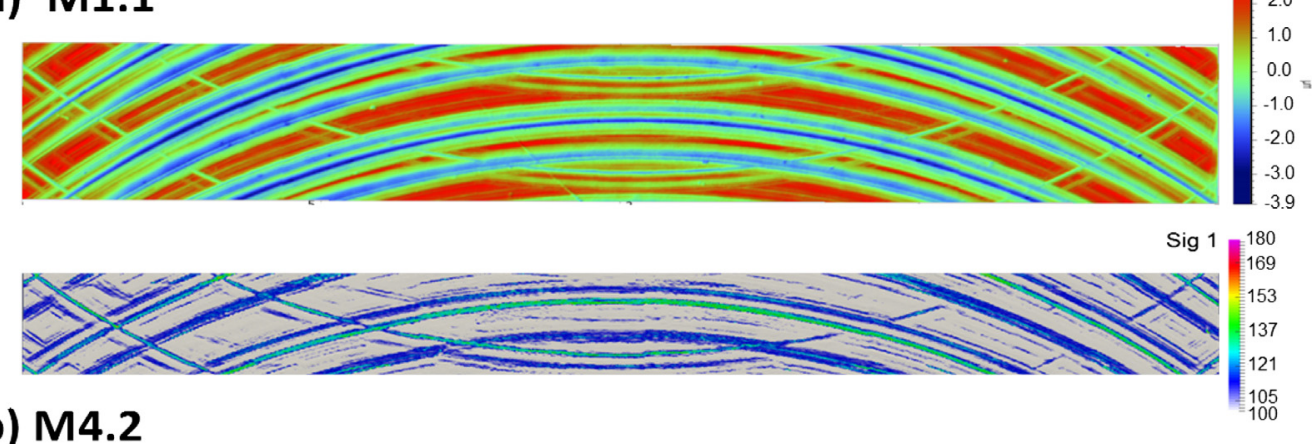

b) M4.2
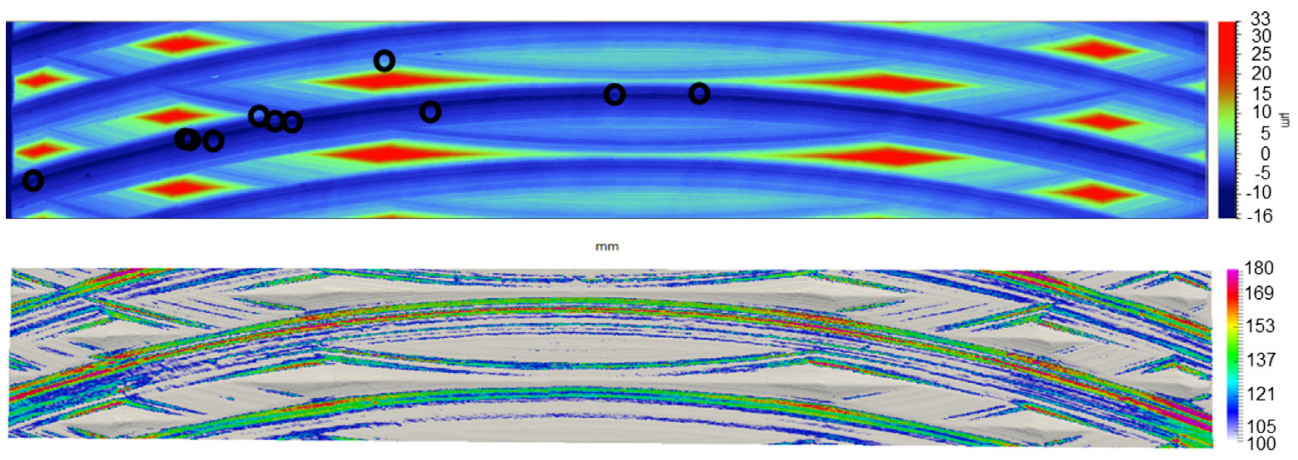

c) M5.5
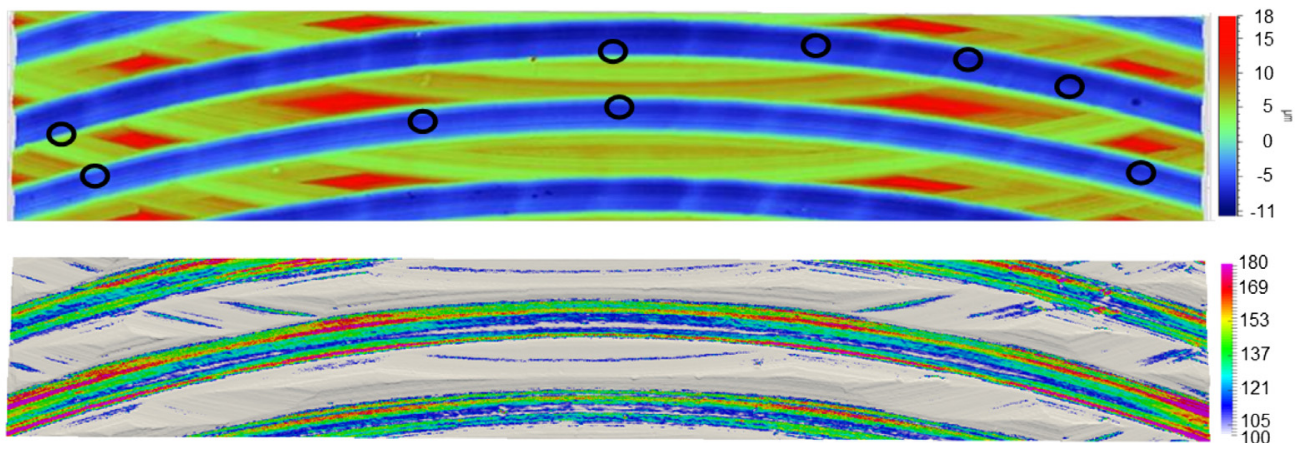

Fig. 21. Comparison between the surface topology and the principal stress distribution obtained via FE simulation for the (a) M1.1 (b) M4.2 and (c) M5.5 surface states.

\section{Predictions for the AA7050 Alloy containing end machined surface states}

The objective of this part is to test the predictivity of the two (surface and volume) approaches in the case of machined surface conditions. The parameters of the two approaches will be those determined in [31] from tests carried out on specimens containing hemispheric defects and presented in Table 8.

For both surface and volume formulations, parameters $H_{m}$ and $K_{t_{\max }}$ need to be identified for each surface state. The periodicity of the profile allows to express the stress heterogeneity factor of the entire specimen as the product of the heterogeneity factor of a cell by the number of cells considered. A cell is seen as a representative area of the investigated surface state (see Fig. 16).

$H_{m s}=\frac{1}{S_{\Omega}}\left[n S_{m} H_{m s_{m}}\right]$

$H_{m v}=\frac{1}{v_{\Omega}}\left[n V_{m} H_{m v_{m}}\right]$

Note that due to the periodicity of the studied surface state, the stress heterogeneity factors $H_{m s_{m}}$ and $H_{m v_{m}}$ calculated on the representative area or volume are equal respectively to the stress heterogeneity factors of the sample $H_{m s}$ and $H_{m v}$.

To identify $H_{m}$ and $K_{t_{\max }}$, finite element simulations are necessary in order to determine the generated stress in each element on the surface or in the considered volume. For that, FE calculations integrating the real profile of the surface state resulting from scans made with the 3D profilometer, are carried out.

The approach followed is shown in Fig. 18 and begins with a profilometric scan of the surface geometry of the specimens. All the scans containing the position and height of each scanned point are recorded using a spatial resolution of $1.9 \mu \mathrm{m}$. After verifying the repeatability of the surface states for the different specimens of each batch, a representative area of the surface condition is selected.

All the scans are recorded using a spatial resolution of $1.9 \mu \mathrm{m}$. A first filtering step conventionally used in profilometry is applied to the raw data to solve measurement problems (missing pixels, aberrant altitude values at certain points, etc.). In addition, a second Gaussian regression filter is applied in order to remove any stress concentration singularities generated by the measurement noise. This technique is usually employed when dealing with geometries inspired from real measurements $[10,16]$. On a global scale, the Gaussian filter used does not change the 
P M1.1 M4.2 M5.5

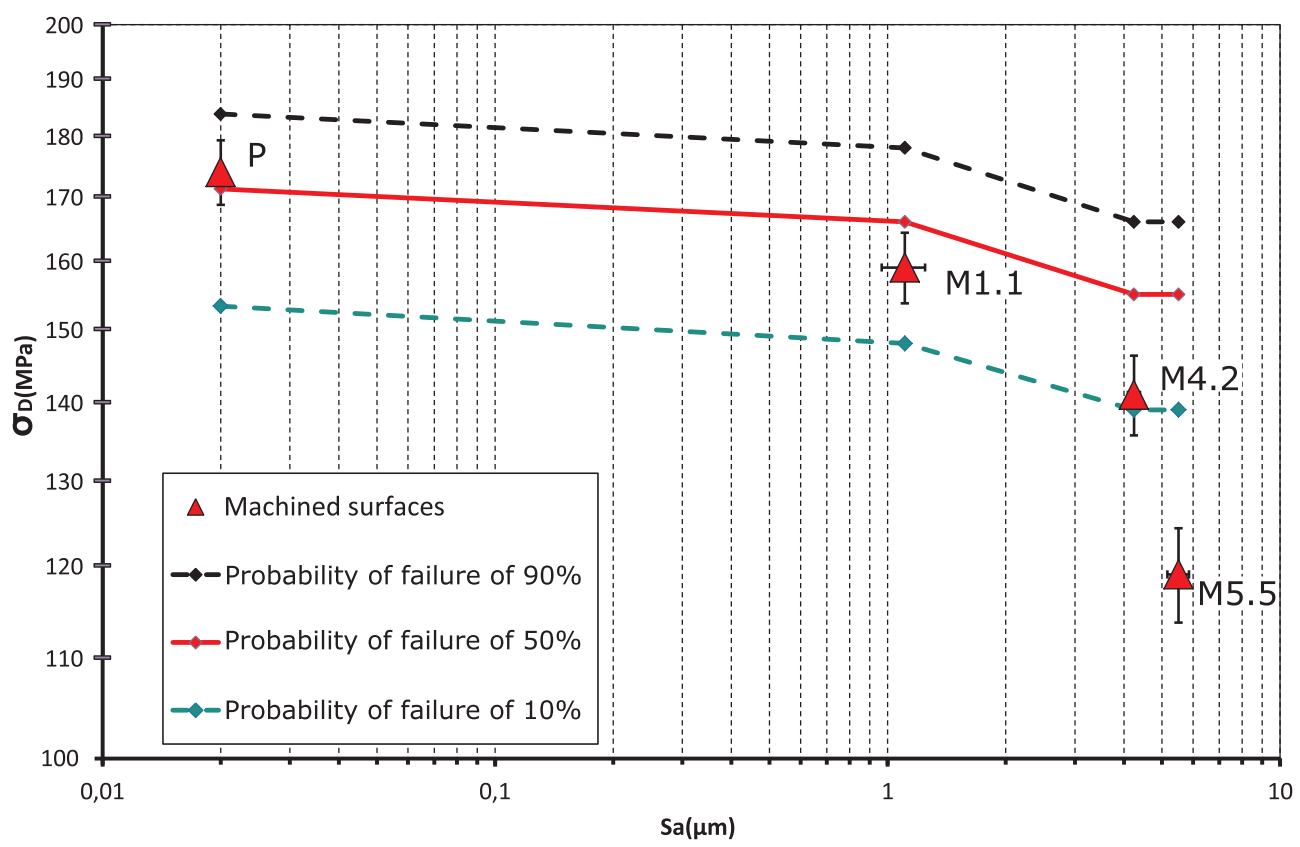

Fig. 22. Comparison between the predictions of the surface approach and the experimental results.

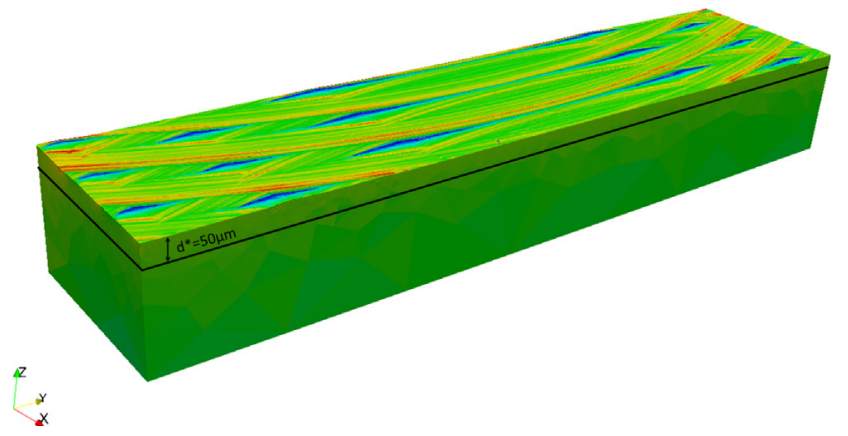

Fig. 23. Illustration of the $d^{*}$ parameter in the Finite Element Model.

surface condition (Fig. 19). On the other hand, at the more local scale, the filter allows to smooth the obtained profile and eliminate the discontinuity and singularities problems generated by the raw measurement process (see Fig. 19).

The cloud of points collected from the area of interest is then transformed into a volume geometry that is meshed afterwards using the GMSH software. The mesh size chosen on the surface is the one given by the 3D scan and is equal to $1.9 \mu \mathrm{m}$.

Elastic calculation is performed using the Finite Element Method. Elements are tetrahedral with reduced integration. Boundary conditions are as follows:

- Displacement Ux $=0$ along of the plane $X=0$ (surface A).

- Displacement Uy $=0$ along of the line $X=0, Y=0$.

- Displacement $\mathrm{Uz}=0$ at the point $X=0, Y=0, Z=0$.

- A bending loading is applied along the surface B (Fig. 20) and is representative of the experimental bending loading applied to specimens.

A post-processing step then makes it possible to extract the stress fields at the surface or in depth and to apply the probabilistic model developed over an area of the size of the cell. Note that in order to avoid boundary effects, the FE calculation is performed over an area larger than the cell size. All results presented in Fig. 21 are obtained applying a nominal maximum stress in bending $\sigma_{a}$ of $100 \mathrm{MPa}$.

Due to the simplicity of the applied loading, the analysis of the stress field is focused on the first principal stress $\sigma_{I}$. In our work, the stress concentration factor is therefore defined on each point by:

$K_{t}=\frac{\sigma_{I}}{\sigma_{a}}$

\subsection{Surface stress field analysis}

The numerical calculation is first carried out for the M1.1 surface state. The comparison of the crack initiation sites with the numerical calculation is not easy given the large number of overlapping machining grooves with shallow depth and width (Fig. 21a). The numerical calculation shows a localized stress concentration at the bottom of the machining grooves. The maximum stress concentration factor value $K_{t}$ for this surface state is of the order of 1.5.

In Fig. 21b and 21c, the surface stress field obtained by numerical simulation is compared to the location of the crack initiation sites of the M4.2 and M5.5 surface states. Fig. 21 shows that for these two batches the maximal principal stress is higher at the bottom of the machining grooves and more importantly on the areas between the highest peaks (areas of high roughness values). This result does not agree with the random location of the crack initiation sites at the bottom of these grooves. This result justifies the choice of a non-local approach to predict fatigue behavior.

Individual measurements of the stress concentration factor along the machining ridges are made for the two surface states M4.2 and M5.5. For both surface states, the stress concentration factors are close and $K_{t}$ varies between 1.2 and 1.7 at the machining grooves. On the other hand, $K_{t}$ reaches values of the order of 1.8 in local areas between the highest peaks. With these values of stress concentration factor, the maximum local stress reaches $270 \mathrm{MPa}$, which remains below the yield stress of the material of $428 \mathrm{MPa}$ (see Section 2.1). The hypothesis of elastic behavior is therefore well verified. Despite their close stress concentration factors, the fatigue strengths of the M4.2 and M5.5 batches are very different, respectively 141 and $119 \mathrm{MPa}$. This result shows the limits of a local approach and the interest of taking into account the entire stress field over the surface of the component. 


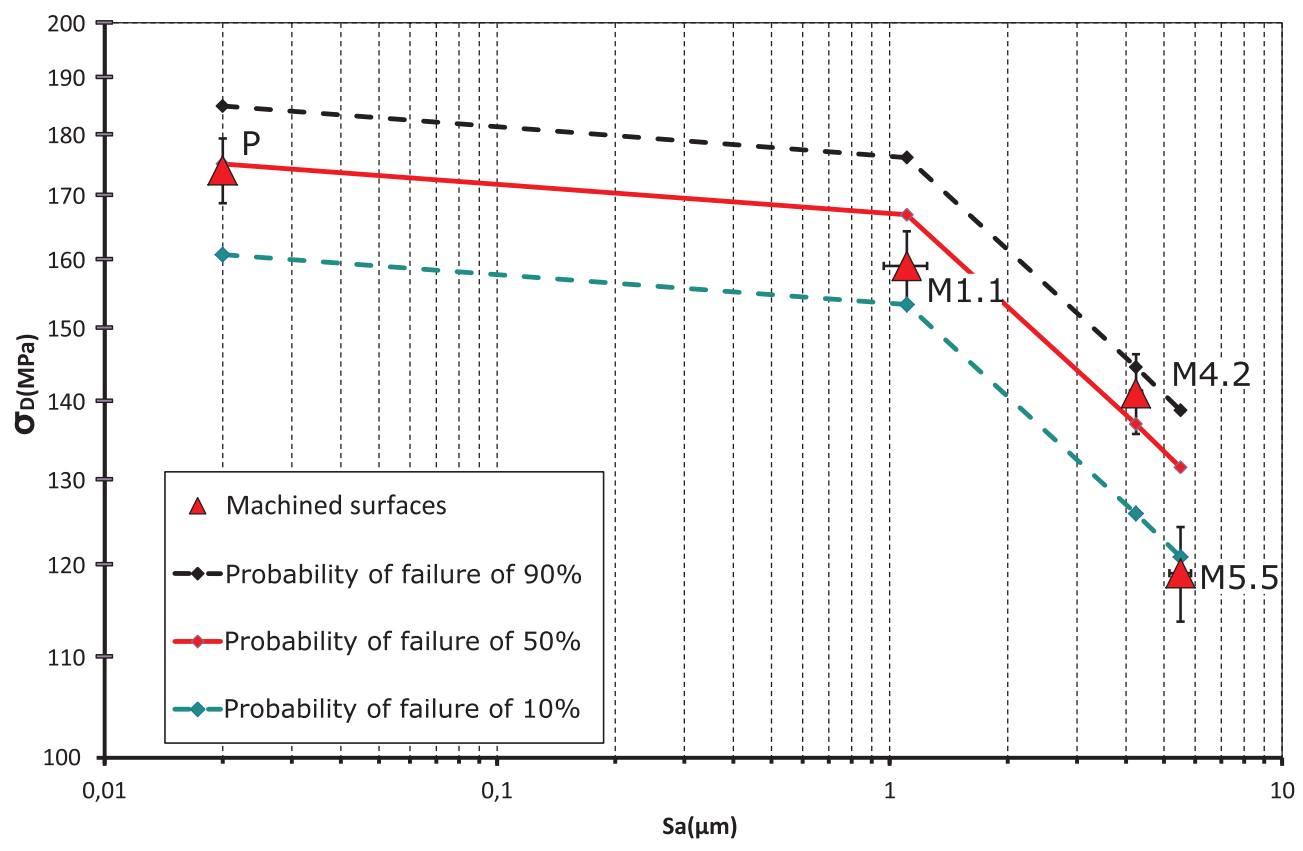

Fig. 24. Comparison between the predictions of the volume approach and the experimental results.

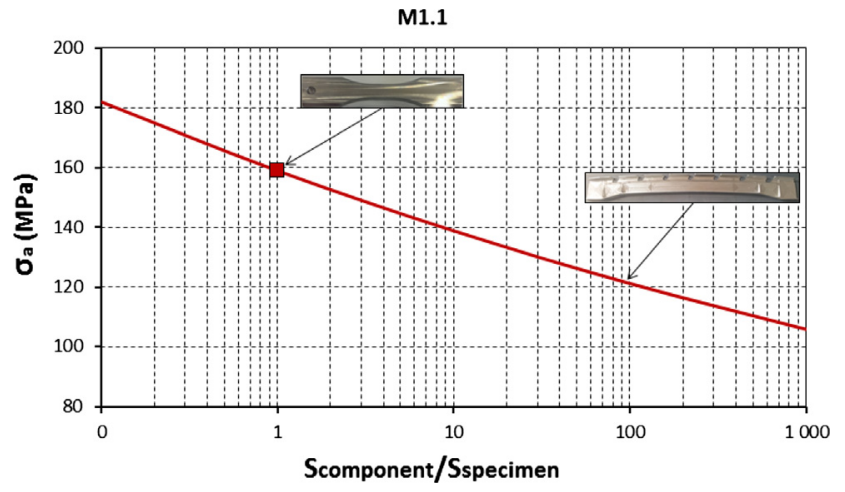

Fig. 25. Evolution of the fatigue strength of a milled component (M1.1 surface state) as a function of the size of the loaded surface. The point corresponds to the experimental fatigue strength on M1.1 test specimens.

\subsection{Prediction of fatigue resistance in the case of machined and polished surface states}

After FE calculations, the values of $H_{m}$ and $K_{t_{\max }}$ are determined for each surface state. The predictions obtained via the surface and the volume approaches are presented in a diagram inspired from the Kitagawa-Takahashi type diagram where the fatigue strength is plotted as a function of the surface roughness $S_{a}$. The error bars of Y and X axis correspond respectively to the standard deviations of the fatigue strength and of the $S_{a}$ value estimated on each batch (Table 4).

For different failure probabilities, the surface approach predictions show a good agreement with the experimental results (Fig. 22) except for the M5.5 surface state where the model incorrectly predicts a better performance than for M4.2 surface state. At a failure probability of $50 \%$ $(\mathrm{PF}=0.5)$, the estimated error between the experimental results and the predictions via the surface approach reaches $30 \%$ for the M5.5 surface state against less than $3 \%$ for the M1.1 surface state and $10 \%$ for the M4.2 surface state. Note that the use of other equivalent stresses than the first principal stress leads to very close predictions of the fatigue behavior (i.e: the scatter between predictions considering the first principal stress, Von-Mises equivalent stress and Tresca equivalent stress is lower than $3 \mathrm{MPa}$ for the different surface states).
The volume approach integrating the stress distribution in a limited volume with a depth $\mathrm{d} *=50 \mu \mathrm{m}$ (Fig. 23) provides better predictions than the surface approach. Volume approach allows to keep the advantages provided by the surface approach in describing the fatigue behavior and to give a better prediction of the low fatigue strength of M5.5 batch (Fig. 24). The predicted fatigue strength for M5.5 surface state is however non conservative with an error of $9 \%$. The difference between the predictions of the two approaches on the batches M4.2 and M5.5 can be explained analyzing the size of the highly stressed area or volume. The highly loaded area where the first principal stress is $20 \%$ higher than the first principal nominal stress applied is close for the two batches $S_{M 5.5}\left[\sigma_{I}>1,2 \sigma_{I, \text { nominal }}\right] \approx 1.1 S_{M 4.2}\left[\sigma_{I}>1,2 \sigma_{I, \text { nominal }}\right]$ and the fatigue limits predicted using the surface approach are almost equal for the two batches studied.

The highly loaded volume is larger for the M5.5 batch compared to the M4.2 batch $V_{M 5.5}\left[\sigma_{I}>1,2 \sigma_{I, \text { nominal }}\right] \approx 1.3 V_{M 4.2}\left[\sigma_{I}>1,2 \sigma_{I, \text { nominal }}\right]$ and the fatigue limit predicted using the limited volume approach is therefore lower for the batch M5.5.

To conclude, the proposed model in its surface and volume configurations, whose parameters have been identified by tests conducted on specimens with artificial defects, is able to predict the fatigue behavior of the P0, M1.1 and M4.2 surface conditions. For the M5.5 batch the volume approach shows more accuracy than the surface approach in predicting the fatigue strength.

\subsection{Prediction of fatigue resistance in the case of different structure size}

The proposed probabilistic model has the advantage of naturally integrating the scale effect and thus being applicable to different sizes of structures. For example, the fatigue strength of an end-milled component, with "standard" industrial surface conditions (M1.1 surface state), and larger than the tested specimen can be identified by considering the ratio between the components loaded surface and the specimens loaded surface (Fig. 25). Fig. 25 illustrates that an increase in the size of the structure generates a decrease in fatigue strength. For instance, a drop of $25 \%$ is expected when the loaded surface increases by a factor of 100 . 


\section{Conclusion and prospects}

The main conclusions of this work can be presented as follows:

- Fully reversed plane bending fatigue tests campaign have been conducted on specimens with different surface roughness levels obtained via end milling process. It is necessary to greatly increase the surface roughness in order to observe a significant decrease in the fatigue strength of the AA7050 alloy.

- The surface roughness $S_{a}$ seems to be the best roughness parameter to characterize the effect of the surface topology on the fatigue behavior of the end milled parts.

- Fatigue strength depends on the local stress concentration as well as on the dimension of machining grooves (scale effect).

- Fatigue strength predictions are in good agreement with the experimental results. The proposed approach based on Weibull's distribution law and the weakest link concept allows to predict with accuracy the fatigue strength for polished specimens as well as specimens with end machined surface states.

As prospects, the proposed criterion will be applied for different conditions:

- The criterion will be applied to other loading cases, in particular multiaxial loading.

- That kind of approach can be applied on other types of materials such as TA6V alloy.

- The proposed criterion will be applied in the case of real components with different sizes and the same machined surface state (scale effect).

\section{Acknowledgments}

This work was carried out within the FUI QUAUSI project with the support of industrial (Dassault Aviation, Europe Technologie, Figeac Aéro, Mecachrome, Spring Technologie, Precise, GEBE2, CETIM) and academic partners (LSN2-IUT Carquefou).

\section{References}

[1] Brunet S. PhD thesis: Influence des contraintes résiduelles induites par usinage sur la tenue en fatigue des matériaux métalliques aéronautiques, Paris, FRANCE: ENSAM Paris; 1991.

2] Shahzad M, Chaussumier M, Chieragatti R, Mabru C, Rezai Aria F. Influence of anodizing process on fatigue life of machined aluminium alloy. Procedia Eng 2010;2:1015-24.

[3] Guillemot N. Prise en compte de l'intégrité de surface pour la prévision de la tenue en fatigue des pièces usinées en fraisage [Ph.D thesis]. Cachan: ENS Cachan; 2010.

[4] Souto-Lebel A, Guillemot N, Lartigue C, Billardon R. Characterization and influence of defect size distribution induced by ball-end finishing milling on fatigue life. Procedia Eng 2011;19:343-8.

[5] Moussaoui K. Influence de l'usinage sur la durée de vie en fatigue de pièces aéronautiques en alliage de titane. Toulouse: Université Toulouse 3 Paul Sabatier; 2013.

[6] Limido J. Etude de l'effet de l'usinage grande vitesse sur la tenue en fatigue de pièces aéronautiques [Ph.D thesis]. Université de Toulouse; 2008.

[7] Tang ZT, Liu ZQ, Pan YZ, Wan Y, Ai X. The influence of tool flank wear on residual stresses induced by milling aluminum alloy. J Mater Process Technol 2009;209:4502-8.

[8] Rao B, Shin YC. Analysis on high-speed face-milling of 7075-T6 aluminum using carbide and diamond cutters. Int J Mach Tools Manuf 2001;41:1763-81.

[9] Campbell CE, Bendersky LA, Boettinger WJ, Ivester R. Microstructural characterization of Al-7075-T651 chips and work pieces produced by high-speed machining. Mater Sci Eng 2006;430(A):15-26.

[10] Suraratchaï M, Limido J, Mabru C, Chieragatti R. Modelling the influence of machined surface roughness on the fatigue life of aluminum alloy. Int J Fatigue 2008;30:2119-26.

[11] Inglis CE. Stresses in a plate due to the presence of cracks and sharp corners. Engineering 1913;95:415.

[12] Arola D, Williams CL. Estimating the fatigue stress concentration factor of machined surfaces. Int J Fatigue 2002;24:923-30.

[13] Neuber H. Theory of notch stresses. s.l.:Office of Technical Services; 1961.

[14] Souto-Lebel A. Rôle de l'intégrité de surface dans la tenue en fatigue d'un acier bainitique après fraisage de finition [Ph.D. thesis]. Cachan: ENS Cachan; 2014.

[15] Murakami Y. Metal fatigue: effects of small defects and nonmetallic inclusions. Elsevier; 2002.

[16] Ås SK. Fatigue life prediction of an aluminum alloy automotive component using finite element analysis of surface topography [Ph.D. thesis]. Norwegian University of Science and Technology; 2006.

[17] Taylor D. Geometrical effects in fatigue: a unifying theoretical model. Int J Fatigue 1999;21(5):413-20.

[18] Taylor D. The theory of critical distances. Eng Fract Mech 2008;75(7):1696-705.

[19] Taylor D. A mechanistic approach to critical-distance methods in notch fatigue. Fatigue Fract Eng Mater Struct 2001;24(4):215-24.

[20] Le VD, Saintier N, Morel F, Bellett D, Osmond P. Investigation of the effect of porosity on the high cycle fatigue behaviour of cast Al-Si alloy by X-ray microtomography. Int J Fatigue 2018;106:24-37.

[21] Gerin B, Pessard E, Morel F, Verdu C. A non-local approach to model the combined effects of forging defects and shot-peening on the fatigue strength of a pearlitic steel. Theroretical Appl Fracture Mech 2018;93:19-32.

[22] Freudenthal AM. Liebowitz H, editor. Fracture, vol. 2. New York: Academic Press; 1968. p. 591-619.

[23] Weibull W. A statistical distribution function of wide applicability. ASME J Appl Mech 1951;18:293-7.

[24] Hild F, Marquis D. A statistical approach to the rupture of brittle materials. Eur J Mech A/Solids 1992;11:753-65.

[25] Chantier I, Bobet V, Billardon R, Hild F. A probabilistic approach to predict the very high-cycle fatigue behaviour of spheroidal graphite cast iron structures. Fatigue Fract Eng Mater Struct 1999;23:173-80.

[26] Bomas H, Linkewitz T, Mayr P. Application of a weakest-link concept to the fatigue limit of the bearing steel SAE 52100 in a bainitic condition. Fatigue Fract Eng Mate Struct 1999;22:733-41.

[27] Delahay T, Palin-Luc T. Estimation of the fatigue strength distribution in high-cycle multiaxial fatigue taking into account the stress-strain gradient effect. Int J Fatigue 2006;28:474-84

[28] Pessard E, Bellet D, Morel F, Koutiri I. A mechanistic approach to the KitagawaTakahashi diagram using a multiaxial probabilistic framework. Eng Fract Mech 2013;109:89-104.

[29] Pessard E, Morel F, Morel A, Bellett D. Modelling the role of non metallic inclusions on the anisotropic fatigue behaviour of forged steel. Int J Fatigue 2011;33:568-77.

[30] Morel F, Huyen N. Plasticity and damage heterogeneity in fatigue. Theor Appl Fract Mech 2008;49:98-127.

[31] Abroug F, Pessard E, Germain G, Morel F. HCF of AA7050 alloy containing surface defects: Study of the statistical size effect. Int J Fatigue 2018;110:81-94.

[32] Kitagawa H, Takahashi S. Applicability of fracture mechanics to very small cracks. In: ASM Proceedings of 2nd international conference on mechanical behaviour of materials. Metalspark, Ohio; 1976, p. 627-31.

[33] Gupta VK, Agnew SR. Fatigue crack surface crystallography near crack initiating particle clusters in precipitation hardened legacy and modern Al-Zn-Mg-Cu alloys. Int J Fatigue 2011;33(9):1159-74.

[34] Dixon WJ, Mood AM. A method for obtaining and analyzing sensitivity data. J Am Stat Assoc 1948:43:108-26.

[35] ISO12107:2012: Metallic materials - Fatigue testing - Statistical planning and analysis of data.

[36] Leach RK. Characterisation of areal surface texture. Berlin: Springer; 2013.

[37] Griffiths B. Manufacturing surface technology: surface integrity and functional performance. London: Prenton Press; 2001.

[38] Weibull W. A statistical theory of the strength of materials. Roy Swed Inst Eng Res Report 1939;151.

[39] Flaceliere L, Morel F. Probabilistic approach in high-cycle multiaxial fatigue: volume and surface effects. Fatigue Fract Eng Mater Struct 2004;27(12):1123-35. 